\title{
EXPERIÊNCIA DE COMPRA ONLINE: EXPLORAÇÕES A PARTIR DO DESIGN THINKING
}

\section{ONLINE SHOPPING EXPERIENCE: EXPLORATIONS FROM DESIGN THINKING}

\author{
Maicom S. Brandão ${ }^{1}$, M. Sc. \\ maicom.brandao@usp.br e http://orcid.org/0000-0002-7798-1922 \\ Oswaldo Miguel $^{3}$, B. Sc. \\ osmiguelth@usb.br https://orcid.org/0000-0002-0126-3019 \\ Tatiana M. Machado ${ }^{2}$, B. Sc. \\ tatimm@usp.br e https://orcid.org/0000-0002-6656-0356 \\ Gabriel H. S. Rampini ${ }^{2}$, M. Sc. \\ gabrielrampini@usp.br e https://orcid.org/0000-0001-8780-7074 \\ Diane Aparecida Reis ${ }^{2}$, M. Sc. \\ diane.reis@hotmail.com e https://orcid.org/0000-0002-5831-2336 \\ ${ }^{1}$ Universidade Federal de São Carlos, São Carlos, Brasil \\ ${ }^{2}$ Universidade de São Paulo, Escola Politécnica, São Paulo, Brasil \\ ${ }^{3}$ Universidade de São Paulo, Escola de Comunicação e Artes, São Paulo, Brasil
}

Design thinking, Experiência do usuário, E-commerce

O presente estudo aborda a melhoria da experiência na compra online por meio do design thinking, identificando e apresentando uma solução para uma das principais dores identificadas nesse meio, que é a ausência da prova física de produtos de vestuário. Considerando os aspectos comportamentais, essenciais para o pensamento de experiência do usuário, a pesquisa identificou que a experimentação dos produtos de vestuário aumenta a confiança para a compra e reduz o risco de troca do produto. A identificação da dor e construção da solução contemplou um conjunto de etapas realizadas dentro da abordagem do design thinking, que foram: uma revisão sistemática da literatura; benchmarkings e análise de dados secundários; entrevistas em profundidade com usuários; uso de ferramentas do design como criação de personas, mapa de empatia, jornada do usuário e ponto de vista; e desenvolvimento e teste de protótipos. Foi identificado que aspectos visuais, como a qualidade e a diversidade de imagens e a disponibilidade de informações, e um sistema de recomendação de tamanho contribuem para a melhoria da experiência de compra online e que podem ser utilizados de forma complementar.

\section{Design thinking, User experience, E-commerce}

This study deals with improving the online shopping experience through the process of design thinking, by identifying and presenting a solution to one of the main pain points identified in this medium, which is the lack of physical proof of clothing products. Considering behavioral aspects, essential for the user experience thinking, the research pointed that the experimenting of the clothing products increases the confidence for the purchase and decreases the risk of product exchange. The identification of the pain and construction of the solution included a set of steps carried out within the design thinking approach, which were: a systematic literature review; benchmarking and secondary data analysis; indepth interviews with users; use of design tools such the creation of personas, empathy map, user journey and point of view; and development and test of prototypes. It was identified that visual aspects, such as quality and variety of images and the availability of information; and a size recommendation system contribute to the improvement of the online shopping experience and can be used in a complementary way. 


\section{Introdução}

O online se tornou um espaço comum de interação, trabalho e de compras. Nesse contexto, o e-commerce é conhecido como a forma de realizar negócios pela internet, seja entre empresas como entre consumidores finais e empresas (CAI et al., 2018).

As projeções de crescimento global do e-commerce para os próximos anos são elevadas, representando um mercado de mais de três milhões de dólares (GRAN VIEW RESEARCH, 2020). Ademais, o comércio online tem se mostrado essencial em grandes períodos de crise, seja de origem econômica, pois permite um alcance de negócio além do local, ou mais recentemente, de origem sanitária, como é o caso do Corona vírus - SARS CoV-2 - que tem restringido a abertura de estabelecimentos por conta do risco de contágio, restando ao $e$ commerce a saída para que os negócios não percam toda sua receita nesse período de pandemia, tanto que tem sido oficialmente recomendado como canal de distribuição por governos e instituições de relevância no cenário internacional como o Banco Mundial (UNGERER et al., 2020). No entanto, atuar no ambiente online representa um desafio tanto para empresas quanto para pesquisadores. Mais ainda, migrar abruptamente de uma estratégia focada em canais físico, para uma totalmente online, demanda esforços múltiplos das empresas, por isso, nesse contexto, soluções simples e rápidas são desejáveis.

Um crescente número de estudos tem buscado entender diversas perspectivas do consumo online, desde motivadores e barreiras para que consumidores optem pelo e-commerce em detrimento dos canais tradicionalmente físicos de varejo (PAPADOPOUOU; KANELLIS; MARTAKOS, 2001; CLEMES; GAN; ZHANG, 2014) até estudos que buscam investigar elementos mais específicos de operação do e-commerce assim como Hudák, Kianičková e Madleňák (2017) fizeram para entender o papel do e-mail marketing para o processo de compra online, ou como Yu et al. (2016) para verificar as práticas de cadeia de suprimentos nesse meio. De uma revisão da literatura passada, Ngau e Wat (2002) identificaram os principais aspectos que estavam relacionados à estruturação desse canal. Uma vertente importante do estudo do e-commerce se dedica em explorar avanços tecnológicos (CHEN; TAN, 2004; IYER; GERMAIN; FRANKWICK, 2004; YOO; YU; JUNG, 2018; LIM; JIN; SRAI, 2018). Por sua vez, outros estudos têm focado no comportamento do consumidor nesse ambiente (KOUFARIS; KAMBIL; LABARBERA, 2001; PAVLOU; CHAI, 2002; MITTAL, 2013).

E é neste contexto que se insere esse estudo. Partindo de uma lógica abdutiva, o presente estudo buscou utilizar o design thinking para identificar facilitadores e barreiras para a criação de uma experiência online para os usuários do e-commerce e elaborar uma proposta de solução para um dos principais desafios da comercialização nesse ambiente, que é a reprodução da experiência de provar itens de vestuário, pouco viável no ambiente online.

O estudo utilizou o design thinking em todo o processo de construção, que contemplou uma revisão sistemática da literatura; benchmarkings e análise de dados secundários; entrevistas em profundidade; uso de ferramentas do design como diagrama de afinidades, jornada do usuário, criação de personas, entre outros; e desenvolvimento e teste de protótipo. O uso do design thinking se mostrou inovador tanto do ponto de vista acadêmico - devido ao baixo número de estudos que abordam esse tema a partir do design thinking, bem como a exploração da principal dor identificada no contexto brasileiro, que é um mercado em ascensão nesse canal - quanto prático - trazendo à luz uma proposta de solução para um problema real e que afeta muitos negócios online - uma vez que, enquanto os retornos de produtos afetam em média $8 \%$ do varejo físico, para o e-commerce essa taxa varia de $15 \%$ podendo chegar até $30 \%$ dependendo do tipo de produto (BHATTACHARYYA, 2018).

O presente artigo está organizado da seguinte forma: a seção um contextualiza a pesquisa e detalha o problema de pesquisa a ser respondido, assim como o breve descritivo do método a ser empregado para tal; a seção dois apresenta uma revisão sobre a experiência de compra online; a seção três contempla os métodos 
de pesquisa utilizados no desenvolvimento do design thinking; a seção quatro evidencia e discute os resultados obtidos; e por fim, a seção cinco traz as conclusões da pesquisa realizada, assim como suas limitações e possibilidades de estudos futuros.

\section{Revisão da literatura}

\subsection{Experiência de compra no e-commerce}

E-commerce é o negócio transacionado eletronicamente entre parceiros de negócios (CAMERON, 1997). Envolve a compra e a venda de informações, produtos e serviços por meio da rede mundial de computadores (KALAKOTA; WHINSTON, 1997; O'BRIEN, 2004). De acordo com Kalakota e Robinson (2002), existem três tipos de e-commerce: inter-organizacional (Business to Business); intraorganizacional (por exemplo, quando envolve a comercialização de empresas de um mesmo grupo, ou entre diferentes plantas de forma online) e organização-consumidor (Business to Consumer). O foco desta pesquisa é o organizaçãoconsumidor, popularmente conhecido como B2C (Business to Consumer).

Apesar de envolver uma atividade tradicional da sociedade, que é a venda e a compra, a comercialização em meios eletrônicos possui diversas especificidades que devem ser observadas pelos atores que atuam nesse canal. Por exemplo, diferentemente dos canais físicos, os produtos ofertados não estão fisicamente disponíveis para a avaliação do consumidor. Nesse sentido, tem sido recorrente estudos que buscam mecanismos de suprir essa diferença por meio da criação de uma boa experiência para o cliente, para que cada vez mais se realizem compras online (CONTRERAS et al., 2015; TSAGKIAS; MURDOCK, 2020). Quando se investiga experiência do usuário, vários aspectos são considerados como o design da visualização, da informação, da interação, além da arquitetura da informação, dos requisitos de conteúdo e dos objetivos do website e do público-alvo (CAI et al., 2018).

Por exemplo, foi verificado que a usabilidade e a acessibilidade possuem elementos que antecedem a criação de uma boa experiência de compra no ambiente online (MAJID; KAMARUDDIN; MANSOR, 2015; SAHI, 2015; GONÇALVES et al., 2018). Em outros casos, sistemas de busca e recomendação mais efetivos também são estudados para atender as necessidades de consumidores cada vez mais novos, e impacientes, que não gostam de procurar exaustivamente na diversidade de opções que existe na web (CAI et al., 2018).

Um desafio existente nesse contexto envolve a construção de experiência de compra para itens de produtos de vestuário, pois se trata de um tipo de produto em que a ausência física do produto se mostra não só como uma barreira para realizar a compra online, mas também aumenta o risco de troca ou devolução pela subjetividade do gosto, pelo caimento ou outros motivos, fazendo com que esse tipo de produto lidere o ranking de retornos no e-commerce, consequentemente, aumentando os custos operacionais (CHE, 1996; SCHIFFER, 2019; CHARLON, 2020).

Vários pesquisadores têm explorado estratégias para melhorar a experiência de compra de itens de vestuário no ambiente online. Por exemplo, uma delas envolve o uso de artefatos físicos que supram o efeito do distanciamento. Guo et al. (2018) apresenta uma solução que permite que um manequim assuma as dimensões corporais de uma pessoa para que simule o caimento das roupas. Yuan et al. (2013) e Hauswiesner, Straka e Reitmayr (2018) exploram soluções dentro dessa mesma estratégia que utiliza representações físicas criadas em meio digital para simulação de cenários. Jiang, Wu, Fu (2018) seguem outra estratégia que está relacionada ao uso de algoritmos de inteligência artificial para identificar exemplos de roupas similares na internet e consolidar sugestões para um possível comprador, buscando expandir a visualização do cliente para além das fotos trazidas pelo website de compra.

Uma terceira estratégia encontrada na literatura tem sido a criação de representações virtuais do corpo humano (avatares) para simular o caimento de roupas (YUAN et al., 2013), ou o uso de informações de 
medidas do corpo para prover recomendações (DING; XU, 2007). No entanto, estudos recentes mostram que, apesar dos esforços, as representações virtuais ainda são vistas como pouco próximas das imagens humanas tradicionais, por exemplo, em vídeos ou fotos, ainda que sejam um caminho possível para melhoria da experiência e aumento de customização (MERLE; SENECAL; ST-ONGE, 2012; MOROZ, 2019).

\section{Método}

O design foi escolhido como disciplina para a condução deste estudo. A escolha do design thinking está associada à natureza da questão, que envolve, antes de tudo, um problema complexo que é a percepção de consumidores sobre qualidade de uma experiência de compra que, por ser online, exclui a interação física e apelativa da função tradicional exercida por equipes de vendas. O design thinking considera, simultaneamente, necessidades humanas e de bem-estar; diversas técnicas e materiais disponíveis; e limitações e oportunidades de um projeto ou negócio (BECKMAN; BARRY, 2007). O método do design thinking é composto essencialmente de três grandes etapas (BROWN; WYATT, 2010):

1. Inspiração - etapa de levantamento inicial de informações para a construção de uma proposta para o problema estabelecido;

2. Ideação - processo de geração, desenvolvimento e teste de ideias que podem levar a soluções;

3. Implementação - momento em que as principais ideias oriundas das etapas anteriores são convertidas em elementos concretos e testadas, traçando uma rota para o mercado.

A Figura 1 ilustra as etapas do processo de design thinking que são detalhados na sequência:

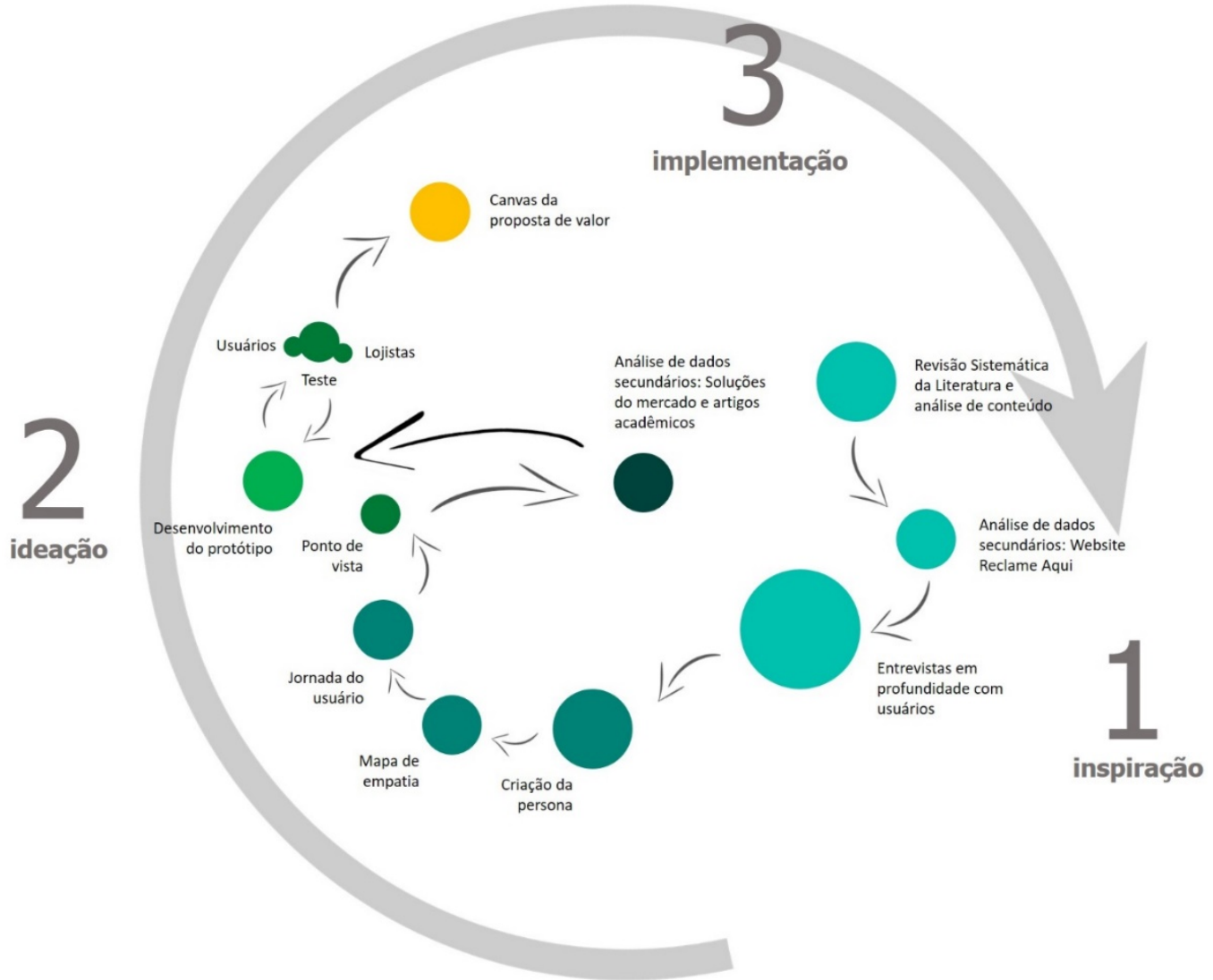

Figura 1 - Etapas do processo de investigação.

Fonte: Elaborado pelos autores. 


\subsection{Inspiração}

Nessa etapa inicial, várias fontes de informações podem ser utilizadas para permitir a inspiração e o entendimento. No caso do presente estudo, duas fontes de informações foram escolhidas:

1. Informações documentais presentes em literaturas acadêmicas, aplicado através do método de Revisão Sistemática da Literatura (RSL), e em websites especializados no assunto;

2. Percepções de consumidores que utilizam o e-commerce para realizar suas compras, utilizando o método de benchmarking e entrevistas.

\subsubsection{Revisão Sistemática da Literatura (RSL)}

A RSL tem sido amplamente utilizada por ser uma forma estruturada de localização e seleção de artigos, aumentando a reprodutibilidade e confiabilidade das buscas, sendo desenvolvida em cinco etapas: planejamento e questões de pesquisa; localização dos estudos; seleção dos estudos; análise e extração de dados; e descrição dos resultados (TRANFIELD; DENYER; SMART, 2003).

O planejamento da pesquisa ocorreu pela delimitação do tema e definição das questões de pesquisa. Considerando o objetivo da pesquisa, verificou-se que ele se encontra associado a três principais eixos: design thinking, user experience e e-commerce. Dessa forma, as questões escolhidas foram: Quais elementos são responsáveis pela criação de uma boa experiência de serviço / produto ao usuário do e-commerce? Quais atuam como barreiras?

Para a localização dos estudos, foram realizadas buscas nas bases de dados da ISI - Web of Science (WoS) e da Scopus através de uma string que está apresentada na Tabela 1, com os códigos extraídos de estudos anteriores da literatura. Nas plataformas de pesquisa, inseriu-se como critérios de filtro: tipo de documento: artigos ou revisões; idioma: inglês; e campos de pesquisa: tópicos que englobam título, resumo e palavraschave. A Web of Science apresentou 327 publicações e a Scopus 383 publicações. Ao serem inseridos no software Mendeley®, verificou-se que 217 publicações estavam em ambas as bases, sendo necessária a exclusão, por duplicidade. Após esse primeiro filtro restaram 493 publicações. As etapas de análise de conteúdo e resultados serão apresentadas na seção quatro.

\begin{tabular}{|l|l|l|l|}
\hline Tema & String & Fonte & $\begin{array}{l}\text { Quantidade de } \\
\text { artigos }\end{array}$ \\
\hline $\begin{array}{l}\text { Design } \\
\text { thinking }\end{array}$ & "design think*" OR "design-think*" & $\begin{array}{l}\text { FLEURY; STABILE; } \\
\text { CARVALHO, 2006 }\end{array}$ & $\begin{array}{l}\text { Scopus: } 1.331 \\
\text { WoS: } 1.043\end{array}$ \\
\hline $\begin{array}{l}\text { Experiência } \\
\text { do usuário }\end{array}$ & $\begin{array}{l}\text { "UX" OR "user experience" OR "experien*" OR "product experience" } \\
\text { OR "human experience" OR "user acceptance" OR "user perception*" } \\
\text { OR "human factors" OR "perceived value" OR "customer value" OR } \\
\text { "emotion*" }\end{array}$ & $\begin{array}{l}\text { VÄÄNÄNEN-VAINIO- } \\
\text { MATTILA; OLSSON; } \\
\text { HÄKKILÄ, 2015 }\end{array}$ & $\begin{array}{l}\text { Scopus: } \\
1.824 .808 \\
\text { WoS: } 1.486 .140\end{array}$ \\
\hline E-commerce & $\begin{array}{l}\text { "EDI" OR "eletronic commerce" OR "e-commerce" OR "eletronic } \\
\text { business" OR "e-business" OR "internet commerce" }\end{array}$ & NGAI; WAT, 2002 & $\begin{array}{l}\text { Scopus: } 19.578 \\
\text { WoS: } 13.948\end{array}$ \\
\hline $\begin{array}{l}\text { String final } \\
\text { (composição } \\
\text { dos temas) }\end{array}$ & $\begin{array}{l}\text { ("design think*" OR "design-think") AND ("UX" OR "user experience" } \\
\text { OR "experien*" OR "product experience" OR "human experience" OR } \\
\text { "perceived value" OR "user perception*" OR "human factors" OR } \\
\text { "eletronic commerce" OR "e-commer value" OR "emotion*") OR ("EDI" OR } \\
\text { "e-business" OR "internet commerce")) }\end{array}$ & Todas "eletronic business" OR \\
\hline
\end{tabular}

Tabela 1 - String utilizada para buscas na RSL.

Fonte: Elaborado pelos autores.

\subsubsection{Análise de dados secundários}

O objetivo dessa etapa foi complementar a investigação sobre os facilitadores e barreiras para a criação de uma boa experiência no e-commerce, bem como identificar, em um segundo momento, as soluções desenvolvidas para atender a principal dor identificada do usuário. Para isso, foram analisados dados 
secundários disponíveis na internet. A primeira pesquisa foi feita no website intitulado "Reclame Aqui" (https://www.reclameaqui.com.br/), que pode ser vista como a principal plataforma de compartilhamento aberta de experiências entre consumidores e empresas no contexto brasileiro, tendo como referência o $e$ commerce.

Na segunda pesquisa, utilizou-se duas strings: fit clothes analyzer e fit clothes analyzer services (traduzido do inglês como serviço analisador de prova de roupas) em buscadores tradicionais de mercado para capturar possíveis soluções desenvolvidas no mercado que minimizem a dor da persona identificada. Todos os retornos do buscador foram classificados entre: soluções de mercado; consultoria tradicional (pessoal); discussões online; textos acadêmicos / revistas sobre o tema; ou fora do escopo. Os resultados de interesse foram alocados ao grupo "soluções de mercado" e a busca terminou quando, na página, a quantidade de retornos desse grupo foi $0 \%$, indicando saturação na busca realizada. Os resultados foram analisados em termos de: foco, que divide as soluções entre recomendação para tamanho de roupa ou recomendação de modelo de produto; acesso, que está relacionado ao fato de a solução ser aberta para acesso pelo público em geral ou ser exclusiva para empresas, integrada aos canais de e-commerce e provendo a experiência in loco; e complexidade, que foi dividida em três níveis dependendo da quantidade e dificuldade de inserção de dados necessária para a utilização da solução - no caso, foi definida como baixa complexidade quando usuário precisa somente selecionar opções pré-estabelecidas e / ou entrar com poucos dados de referência; média quando existe a necessidade de inserir fotos ou arquivos adicionais; e alta quando necessita uma varredura digital do corpo do usuário.

\subsubsection{Entrevistas}

As entrevistas foram desenvolvidas com o objetivo de captar as percepções dos usuários sobre experiências positivas e negativas de compra online, entendendo quais seriam os motivadores para essas percepções. A entrevista tem sido uma técnica de pesquisa muito utilizada no contexto das pesquisas qualitativas por permitir coletar dados, captar a percepção de indivíduos e sua interpretação em detalhes sobre uma determinada problemática. Assim, obter maior riqueza de conhecimento sobre esses indivíduos e ganhar a empatia com suas dores. No entanto, devem ser atentados os vieses associados às questões mal elaboradas, imprecisões do relato do entrevistado e reflexibilidade (KAJORNBOON, 2005; YIN, 2011; ALSHENQEETI, 2014).

Por conta do objetivo da pesquisa, optou-se pelo tipo de entrevista semiestruturada, que é suficiente para permitir maior aprofundamento na etapa inicial do estudo, mas que, por ter já temas e questões iniciais elaboradas, pode ser conduzida sob certa sistematização (KAJORNBOON, 2005). Por sua vez, para reduzir os riscos de vieses da entrevista, foi elaborado um roteiro de entrevista em um grupo de quatro pesquisadores, que também foram responsáveis pela coleta dos dados da entrevista, reduzindo o efeito do viés associado à coleta por uma única pessoa. A estratégia adotada na pesquisa foi a de generalização do tema, partindo da investigação de uma experiência recente para familiarizar o entrevistado com o contexto e depois partindo para questões mais abertas sobre experiências passadas no e-commerce. Um teste piloto foi realizado por um dos pesquisadores a fim de validar a clareza e conteúdo das respostas. Foram realizadas 12 entrevistas em profundidade com usuários de e-commerce da cidade de São Paulo, nove do sexo feminino e três do masculino com faixa etária variando de 22 até 39 anos. A maior parte dos entrevistados compra, em média, entre 1-2 vezes no mês por meio do comércio online. Por conta do caráter exploratório, a análise do resultado das entrevistas não partiu de uma lista inicial de temas, mas a partir da leitura, interpretação e discussão dos resultados obtidos pelos pesquisadores, permitindo identificar um conjunto de temas transversais aos discursos dos entrevistados. Esses temas compuseram o conjunto de informações levantadas na etapa de inspiração do design thinking. 


\subsubsection{Síntese do repertório obtido}

Os dados obtidos pela revisão sistemática, análise de dados secundários e entrevistas foram posteriormente organizados e sintetizados para a construção de visões interpretativas do problema, que são: diagrama de afinidades; persona; mapa de empatia; jornada do usuário; e ponto de vista.

Primeiramente, foi elaborado o diagrama de afinidades que é uma ferramenta do design thinking que organiza ideias em grandes blocos que facilitam o estabelecimento de atividades futuras do processo (VIANNA et al., 2012). Nesse estudo, as entrevistas e as análises de dados secundários contribuíram para o aumento de repertório dos pesquisadores, que realizaram uma atividade em conjunto de brainstorming para expor seus entendimentos sobre os elementos que contribuem e prejudicam a construção de uma boa experiência no e-commerce por meio de um encontro virtual em uma plataforma de interação colaborativa. As ideias construídas no brainstorming foram separadas em quatro principais grupos: a) citações importantes: agrupando falas de usuários ou trechos de textos memoráveis identificados na inspiração; b) padrões e temas notados: ideias sintetizadas e padrões localizados; c) surpresas e contradições percebidas: pontos de divergência entre a expectativa dos pesquisadores e a realidade captada; e d) explorar mais: pontos que surgiram, mas que não foram totalmente compreendidos na etapa anterior.

Depois foi criada uma persona de referência. A criação de personas é uma característica dos estudos centrado em humanos. Logo, a persona é uma pessoa fictícia que representa um perfil importante dentro do contexto estudado (VIANNA et al., 2012; BRENNER; UEBERNICKEL; ABRELL, 2016). No caso desse projeto, a persona criada foi do tipo focal (OLSEN, 2004), ou seja, um usuário característico do comércio online. A persona pode ser caracterizada a partir de diversos atributos (OLSEN, 2004) e para esse projeto foram escolhidos aqueles que fossem suficientes para sua representação, a saber: idade; cidade; frequência média de compra online; motivações (longo prazo); objetivos (curto prazo); principais problemas e frustrações; particularidades; comportamentos e principais tarefas.

Então, foi criado também um mapa de empatia, que é uma ferramenta de design thinking composta por quatro categorias principais focadas nas ações da persona: o que a persona diz (frases mencionadas), faz (comportamentos observados), acha (pensamentos e pressupostos) e sente (emoções) (BRENNER; UEBERNICKEL; ABRELL, 2016).

Um outro ponto importante de síntese é o da criação de uma jornada do usuário (LEMON; VERHOEF, 2016) que é uma representação gráfica dos elementos que envolvem o usuário durante a sua experiência (HOWARD, 2014). De forma geral, a jornada contém elementos como: tarefas desempenhadas pela persona; objetivos dessa persona em cada tarefa; suas dores; seus sentimentos; principais fases da jornada; e touchpoints, que podem ser interações externas da persona durante a experiência (LEMON; VERHOEF, 2016).

Por fim, como síntese de todo o processo, foi estabelecido o ponto de vista da persona, resumindo a sua principal motivação, sua principal dor e seu resultado esperado a partir da experiência vivida. Permitindo assim seguir com a pesquisa, passando para a próxima fase, a ideação.

\subsection{Ideação}

Brown (2010) apresenta a ideação como um segundo momento no desenvolvimento de um projeto conduzido por meio do design thinking. Nesse momento, as informações organizadas e sintetizadas obtidas na etapa de inspiração forneceram repertório para uma das atividades principais da ideação, que é o brainstorming. O brainstorming tem sido utilizado como uma técnica para encorajar o pensamento criativo na busca por soluções. Por essa razão diversos autores defendem que quanto mais heterogêneo um grupo em 
termos de formações, maior tende a ser a riqueza de possibilidades geradas por um brainstorming (FURNHAM,2000; BROWN; WYATT, 2010; VIANNA et al., 2012; GLEN et al., 2015).

No caso deste estudo, o brainstorming ocorreu por meio de um encontro virtual entre os membros do grupo dentro de uma plataforma de interação colaborativa. Inicialmente, cada membro do grupo anotou em post-its (brainwriting - segundo Tschimmel, 2012) os principais elementos que consideraram importantes na construção da experiência de compra online a partir do repertório adquirido na etapa de inspiração. Em seguida, cada integrante apresentou para os demais suas propostas de solução da dor da persona e após isso foi feita uma discussão sobre os pontos levantados, identificando convergências e dissonâncias. As ideias não repetidas foram mantidas e organizadas em dois painéis, um que as separava entre atributos necessários e desejáveis para a criação de uma boa experiência e outro, que era uma matriz de esforço em relação ao impacto de cada proposta. As ideias então foram avaliadas e algumas se mostraram mais promissoras em resolver as principais dores da persona e por isso foram levadas para o terceiro espaço de processo de design, que é o da implementação.

\subsection{Implementação}

Após o brainstorming e a categorização das ideias na matriz de esforço e impacto, seis principais ideias foram elencadas pelo grupo como mais promissoras em atender as principais dores das personas. Essas ideias estavam relacionadas principalmente com a complementaridade de plataformas na criação da experiência; na visualização dos produtos; na interface da assistência prestada no ambiente online para o consumidor; nos mecanismos de monitoramento em tempo real do pedido; e nas propostas de sugestão de compra com base em atributos humanos e técnicos. Tendo como base que a principal dor identificada na persona foi a da insegurança sobre a compra de produtos de vestuário no ambiente online, a proposta escolhida para ser melhor elaborada foi aquela que propunha um mecanismo de aproximação online da experiência de um provador, de loja física, para o usuário do e-commerce.

Assim, foi construído um protótipo de baixa fidelidade no programa Marvel (https://marvelapp.com/). Um protótipo de baixa fidelidade consiste em um esboço rápido, chamado de "sujo", que serve para visualizar uma ideia; o investimento na construção deste é baixo, sem tanta atenção aos detalhes, o que diferencia-o de um protótipo de "alta fidelidade", e o objetivo a ser alcançado é construir algo que possa ser exibido para outras pessoas que devem ser capazes de reagir com feedback ao que foi construído. Na literatura, também pode ser chamado de Rapid Prototyping, termo usado por Brown (2010). O protótipo de baixa fidelidade construído consistia de duas telas em que a primeira apresentava uma visualização tradicional de websites de e-commerce com a exposição de um produto e após apertar um botão de "prove", o usuário era direcionado para uma segunda tela que solicitava medidas do peso e altura da pessoa. Esse protótipo contribuiu para materializar a ideia inicial e uma vez aprovado pelo grupo, a construção desse protótipo foi refinada em uma plataforma de design online, chamada Axure (https://www.axure.com/). Nesse momento, foi escolhido um produto para o teste - que, por simplicidade e universalidade de uso, foi uma camisa branca - e foram pesquisadas imagens na internet com modelos de diversos pesos e medidas usando camisas brancas similares para indicar que se tratava do mesmo produto. Essas imagens foram importadas para a plataforma online e posteriormente foram agrupadas em uma sequência lógica de compra, similar àquela utilizada no protótipo de baixa fidelidade, mas agora servindo como base para a criação do PMV (tradução do inglês, Minimum Viable Product).

O PMV é uma representação inicial e básica do produto criada e utilizada para aprender mais sobre a solução proposta e validar um conjunto de hipóteses acerca da capacidade do produto em resolver as dores da persona, e é definido por Ries (2009) como a versão de um novo produto utilizada para coletar informações e gerar aprendizado sobre os potenciais clientes com o menor esforço possível. No contexto do design, é um elemento essencial para dar velocidade no processo de desenvolvimento, pois permite a revisão, em caso de reprova do teste, de forma rápida e pouco custos, aumentando assim a frequência de iteração em direção a 
uma solução mais refinada e adequada (DUC; ABRAHAMSSON, 2016). Foram aplicados dez testes do protótipo desenvolvido para verificar o atendimento dos objetivos da solução.

\section{Resultados e discussão}

\subsection{Revisão Sistemática da Literatura (RSL)}

\subsubsection{Análise descritiva}

$\mathrm{Na}$ análise descritiva foram elaboradas estatísticas descritivas, tais como rede de autores, periódicos com maior quantidade de publicação e quantidade de publicações por ano, com foco nas variáveis anteriormente apresentadas na Tabela 1. A rede com os autores mais citados foi confeccionada com o auxílio do software VOSviewer ${ }^{\circledR}$ sobre a amostra parcial de 493 artigos visando identificar quais autores são os mais influentes nesta área. Esta rede apresentada na Figura 2 identificou que o pesquisador Tim Brown é a maior referência no assunto, sendo citado 158 vezes. Em seguida tem-se os pesquisadores Nigel Cross, Kees Dorst e Richard Buchanan citados respectivamente 70, 56 e 41 vezes. Sendo assim, é possível considerar que os estudos a respeito do tema deste artigo possuem como base as pesquisas desenvolvidas por estes 4 autores.

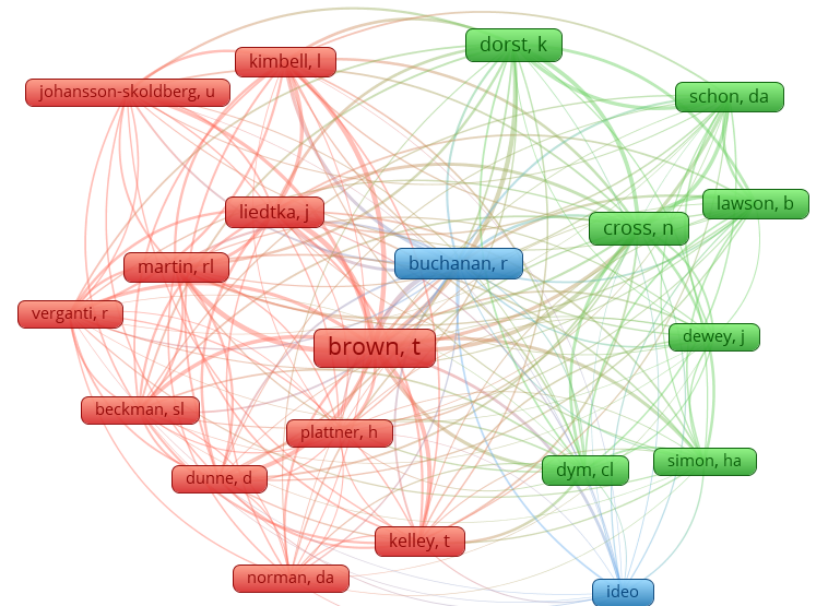

Figura 2- Rede de autores mais citados nos artigos. Fonte: Elaborado pelos autores.

A rede de autores contribuiu para incluir na leitura total o conjunto de autores mais citados, que seriam as referências nessa disciplina. Em seguida, foram analisados os títulos e os resumos de todos os 493 artigos Nesse momento, foi realizado um segundo filtro pelos pesquisadores de caráter conceitual, selecionando artigos, a partir da leitura do título e resumo, que apresentassem elementos que contribuíssem para a construção de uma boa experiência do usuário - não necessariamente no e-commerce - pela aplicação do método do design thinking ou artigos que tiveram a aplicação do design thinking no contexto do comércio online. Após este filtro restaram 49 artigos que compuseram a amostra final apresentada na Figura 3. 


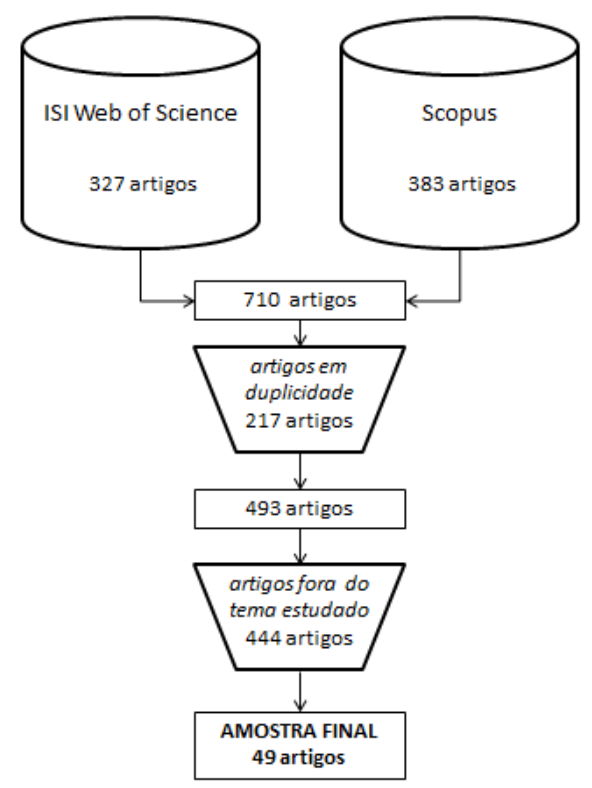

Figura 3 - Resumo do processo de revisão sistemática da literatura.

Fonte: Elaborado pelos autores.

Considerando a amostra final, identificou-se que os 49 artigos foram publicados em 47 periódicos distintos, destacando assim a difusão do assunto entre os periódicos. Somente os periódicos Design Studies e Creativity and Innovation Management publicaram dois artigos da amostra. Salienta-se que, ao se verificar o fator de impacto, os periódicos destacados possuem uma avaliação relevante na área, devendo ser consultados prioritariamente por acadêmicos que desejam pesquisar e publicar na linha temática apresentada neste artigo.

Os artigos da amostra final então foram lidos e as informações extraídas para a análise de conteúdo.

\subsubsection{Análise de conteúdo}

A análise de conteúdo dos artigos selecionados na amostra final ocorreu por meio da leitura em sua totalidade dos 49 artigos. Os facilitadores para a construção de uma boa experiência foram listados, agrupados em categorias que representassem um mesmo conceito e analisados a partir similaridade calculada pelo índice de Jaccard.

Os facilitadores foram agrupados da seguinte forma. Para a solução encontrada no processo de design thinking: foco no ser-humano; sustentabilidade; simplicidade; envolvimento do usuário; avaliação contínua; aspectos visuais; segurança; acessibilidade; integração; e uso de tecnologia. Para o processo de construção da solução: uso de tecnologia; desenvolvimento ágil; integração; análise crítica da solução; ecossistema de inovação; envolvimento do usuário; treinamento em design thinking; conformidade com normas; e mercado. Os facilitadores mais frequentes na amostra de estudos analisados foram: foco no ser-humano (27\%) (solução); avaliação contínua (14\%) (solução); integração (16\%) (processo); e envolvimento do usuário $(16 \%)$ (processo). Os grupos de facilitadores foram criados a partir de agrupamentos realizados com as informações extraídas pela leitura dos artigos.

Verificou-se algumas relações com alta similaridade, como é do foco no ser-humano (solução) e envolvimento do usuário (processo), indicando a relação com o usuário no processo e na solução. A coocorrência dos termos sugere que o envolvimento do usuário desde o início do projeto é parte fundamental para a construção de uma solução como foco no ser-humano. Vários autores destacam o papel importante 
que existe no envolvimento do usuário durante todo o processo para garantir que o problema escolhido seja relevante para o usuário e as dores desse usuário sejam efetivamente captadas (STEPHENS; BOLAND, 2015; CLACK et al., 2019; EINES; VATNE, 2019).

Uma outra associação de destaque nos artigos analisados foi a da integração da solução com a imersão do processo em um ecossistema de inovação. Desenvolver uma solução que integre diferentes sistemas é visto como algo positivo em diversos contextos, por exemplo, Shen (2019) apresenta o conceito de "polvo digital", que seria a capacidade de coletar informações de diferentes fontes e sistemas, agrupando-as de uma forma inteligente. No entanto, vários autores destacam como necessário existir uma cultura aberta à inovação para que essas possibilidades de integração ocorram (CAMERE; BORDEGONI, 2015; LIN; CHENG, 2015).

Outra relação de proximidade que existe é entre, no contexto da solução, do envolvimento dos usuários com aspectos visuais. O apelo visual da solução mostra-se como um ponto importante a ser explorado em desenvolvimentos de design, pois muitas vezes facilita o uso da solução pelo usuário ou fornece mecanismos de identificação rápida da informação relevante. Newhook et al (2015) e Stephens e Boland (2015) destacam a importância de uso de imagens de boa qualidade e Harun et al. (2019) mencionam a utilização de vídeos como forma de envolver o usuário. Ainda sobre o estudo realizado por Harun et al. (2019) destaca-se o problema de estudo abordado pelo design thinking que foi a representação da experimentação de alimentação para turistas considerando um meio digital. Nesse estudo, os autores trouxeram uma solução que além de apresentar fotos dos alimentos que compõe os pratos locais, trouxeram também vídeos representando a experimentação e por meio da expressão facial do ator que estava provando, fornecendo uma pista do tipo de comida, por exemplo, suave, apimentada, etc. e ainda que essa percepção seja relativamente subjetiva, os autores conseguiram auxiliar os turistas nas escolhas dos pratos.

$\mathrm{Na}$ análise de conteúdo, verificou-se que a maior parte dos estudos tinha o foco nos facilitadores para a criação da boa experiência, identificando-se poucas barreiras, que foram complementadas pela análise de dados secundários no website "Reclame aqui".

\subsection{Análise de dados secundários}

\subsubsection{Barreiras para a construção de uma boa experiência no e-commerce}

Com base na análise descritiva de dados secundários obtidos a partir do website "Reclame Aqui" construiuse a Tabela . A análise dos diversos tipos de problemas permitiu identificar cinco principais origens, que são: logística; produto; assistência; propaganda e marketing; e outro.

\begin{tabular}{|l|l|}
\hline Origem & Quantidade de ocorrências \\
\hline Logística & 64.837 \\
\hline Produto & 43.214 \\
\hline Outro & 28.503 \\
\hline Assistência & 24.157 \\
\hline Propaganda e Marketing & 3.919 \\
\hline Total Geral & $\mathbf{1 6 4 . 6 3 0}$ \\
\hline
\end{tabular}

Tabela 2 - Agrupamento dos problemas identificados na compra online.

Fonte: Elaborado pelos autores a partir de dados do website "Reclame aqui" obtidos em 04/04/2020.

Com base nos resultados, o principal grupo reclamado da experiência online é o da logística (39\% do total). De fato, a maior parte relata atraso nas entregas, não recebimento de produtos ou problemas na troca ou devolução de produtos, que juntos compõem 37\% dos 39\% cobertos pela origem logística, o que revela o peso que esse aspecto desempenha na construção de uma experiência pelo cliente. Nesse sentido, toda movimentação adicional, por exemplo, por trocas ou devoluções de produtos aumenta o risco logístico de existir algum problema durante a experiência. De certa forma, garantir um bom nível de serviço logístico, 
mais do que uma qualidade, cada vez tem se tornado requisito primário de operação nesse mercado online, de modo que ter uma baixa qualidade de serviço logístico seria suficiente para indicar perda de vendas futuras.

O segundo grupo com maior quantidade de reclamações é o do produto, mais especificamente relacionado à qualidade do produto. $\mathrm{O}$ terceiro grupo de reclamações compõem um conjunto variado de origens, que muitas vezes são muito específicas, por isso estão agrupados genericamente como "outros". Apesar disso, pelo tipo de produto em que mais ocorre - moda feminina e eletrodoméstico, podem existir indícios do que se trata. Por exemplo, é um tema comum no contexto de vestuário a dificuldade de compra online, pois muitas vezes os consumidores não gostam do produto, o que pode ser uma fonte de reclamação, quando existe dificuldade para fazer esse retorno. Em termos de eletrodomésticos, pode existir dificuldade em manusear o produto ou mesmo entender o manual de instruções e por isso gerar algum tipo de sentimento negativo para o usuário ao tentar usar o produto. $\mathrm{O}$ quarto tema identificado foi a assistência pós-venda. Por fim, a questão da propaganda enganosa é um último tópico identificado, e daí existem mecanismos legais que dão suporte para que o consumidor reclame legalmente sobre o ponto que se sentir prejudicado.

\subsubsection{Soluções de mercado}

Com o objetivo de identificar as soluções existentes no mercado para atender a principal dor da persona criada, que era a dificuldade e insegurança de comprar roupas online pela falta da prova, foram identificadas oito possíveis soluções elegíveis a partir de uma busca sistemática na internet. Os resultados deste agrupamento são apresentados na Figura 2.

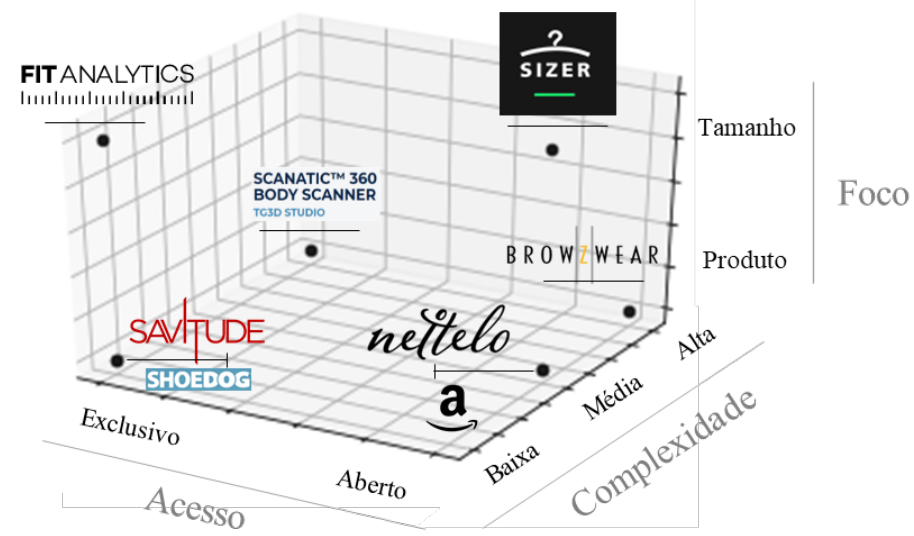

Figura 2 - Síntese das soluções localizadas de acordo com critérios de avaliação.

Fonte: Elaborado pelos autores.

De forma geral, as soluções variam tanto na proposta quanto no modelo de negócio em que se fundamentam. Por exemplo, quando se considera o acesso, verifica-se que algumas empresas optaram por permitir o uso aberto de suas soluções, como é o caso do Sizer, Netello, StyleSnap e Browzwear - em que a solução aberta é mais limitada, mas ainda assim permite que os usuários possam obter informações de medidas do corpo sem necessariamente estarem imersas em uma experiência de compra online. Por sua vez, outras soluções como a Fit Finder, AI Curator, Scanatic 360 e Shoedog são associadas à empresas e ocorrem no momento de imersão da compra, o que de certa forma, pode fazer mais sentido para um sistema de recomendação, afinal prover a informação sem uma ponte evidente com o produto a ser consumido pode ser uma armadilha e gerar frustração no usuário que se apega aos resultados das soluções para tomar uma decisão mais genérica, simplesmente porque, principalmente em realidades como a brasileira, não existe uma padronização das medidas de peças de vestuário amplamente seguida. 
Por sua vez, quando se considera a complexidade de uso, verifica-se que algumas soluções são mais precisas, como é o caso da Scanatic 360, que varre o corpo de um usuário com um escâner e projeta o seu perfil idêntico em um software, até outras mais gerais, como a Fit Finder, AI Curator e Shoedog que lidam com extensivas bases de dados e inteligência artificial para prover a melhor recomendação com o menor esforço, que nesse caso foi estabelecido como aquele em que o usuário precisa somente escolher entre opções que mais se aproximam da sua realidade e/ou inserir informações básica de medidas. Na complexidade média, estão as soluções do Sizer, Netelleo e StyleSnap, nas quais o usuário precisa inserir alguma imagem que reflita seu corpo e/ou preferências. Nesse caso, assume-se que quanto menor a complexidade, melhor seria para o usuário, afinal seria necessário menos esforço para obter o resultado esperado, aumentando a acessibilidade.

Por fim, considerando o sistema de recomendação, verificou-se que existem dois grandes grupos: um focado essencialmente na indicação de tamanhos de roupas, como são os casos do Sizer e Fit Finder, e outro focado na recomendação de produtos, como são os demais. Neste ponto, entende-se que há uma compensação inerente nas abordagens de recomendações escolhidas, porque, enquanto no caso do tamanho possivelmente limitar a expansão da compra - ainda que o Fit Finder traga opções de produtos similares - no caso dos demais, em que se insere informações previamente e o sistema gera uma lista de recomendações de produtos, o usuário pode sentir que teve sua autonomia de escolha limitada ou ainda não ter a oportunidade de percorrer as diversas ofertas da empresa e consequentemente a empresa pode perder vendas por incapacidade de sugerir estilos que atenda o gosto do consumidor. Por isso, considerando a dor da persona, entende-se que a solução existente no mercado que mais aproxima da necessidade identificada é a do Fit Finder, seguida pela do Sizer.

Uma observação pertinente nesse estágio é a de que as ferramentas encontradas no mercado no mercado se aproximam dos avanços trazidos, de forma geral, pela literatura, dentro da problemática explorada neste estudo, que é a prova de roupa online. Uma revisita à literatura resultou em um conjunto de estudos que basicamente exploravam pontos que convergem na melhoria das ferramentas existentes no mercado. Por exemplo, Hauswiesner, Straka, Reirmayr, (2013); Yuan et al. (2013) e Guo et al. (2018) se aproximam da proposta de Scanatic 360 e Nettelo ao usar dispositivos físicos no processo de construção da recomendação, ainda que por estratégias diferentes. Jiang, $\mathrm{Wu}, \mathrm{Fu}$ (2018) está relacionado à proposta da Amazon ao recomendar acessórios que combinem com determinada roupa desejada. Li et al (2017) explora aspectos de ajuste da roupa a partir de um avatar virtual, que é a base de análise existente no Nettelo. Dayik, Colak e Yuksel (2016) se aproximam da proposta do Sizer ao usar um monitor virtual em que as pessoas possam enxergar as roupas desejadas em seus corpos. Ding e Xu (2007) utilizam somente informações e medidas similares ao Fit Analyzer para recomendações. Dessa forma, essas similaridades identificadas sugerem que as inovações que estão sendo trazidas pelo meio acadêmico servem como melhorias às soluções atuais. Destaca-se também a presença de outros estudos mais gerais que abordam o tema da prova de roupa online sobre o aspecto comportamental, por exemplo, Moroz (2019) explorou o sentimento dos consumidores da geração Y sobre os resultados de soluções análogas às encontradas nas soluções de mercado para a prova de roupa e verificou que, enquanto as soluções que sobrepõem roupas de interesse em fotos tiradas pelos consumidores não geram tanta confiança, os casos de uso de avatar 3D são vistos como distantes das pessoas, pois não possuem expressões faciais similares às presentes em humanos e nem, nos casos avaliados, possuíam cabelos, o que dificulta maior obtenção de segurança no momento da compra. Por fim, Merle, Senecal e ST-Onge (2012) destacam o papel da customização no uso das ferramentas de virtuais do setor de vestuário e posicionam a percepção do corpo e a semelhança dos modelos com os usuários como um critério importante na intenção de compra. 


\subsection{Entrevistas}

\subsubsection{Caracterização dos entrevistados}

Foram realizadas 12 entrevistas diretas com o público alvo como sendo o de pessoas de metrópoles com idade superior a 20 anos, como mencionado no segmento 3.1.3. As entrevistas foram feitas individualmente por vídeo chamada e analisadas em conjunto, a partir das quais diversos temas foram identificados e são apresentados abaixo.

\subsubsection{Tipo de produto e motivadores}

Os entrevistados revelaram comprar virtualmente diversos tipos de produtos. O critério de decisão se baseia em aspectos objetivos - especificações técnicas e comparações de preço, informações tidas como mais fáceis de se encontrar online - e existe receio em compras onde os aspectos subjetivos são mais decisivos questionamentos sensoriais ou pessoais, difíceis de avaliar sem contato físico com o produto. Um ponto avaliado como uma vantagem foi o conforto por não precisar se deslocar fisicamente e economia de tempo e dinheiro: "No site, compro em 5 minutos se sei o que eu quero" (Entrevistado 5). Muitas dessas percepções se baseiam em experiências passadas ou pelo contato constante com promoções divulgadas digitalmente.

\subsubsection{Logística e visibilidade do processo}

Verificou-se alta exigência quanto à qualidade da logística esperada de uma empresa que atua no comércio eletrônico. De forma geral, os entrevistados esperam ou receber o produto antecipadamente, ou na data prevista conforme mencionado pelo Entrevistado 12, "[...] gosto quando o produto chega bem antes do esperado, ou quando a entrega é em um dia", e pelo Entrevistado 9, "[...] poderiam melhorar na acuracidade da entrega, o que mais frustra nesse processo é criar a expectativa para entrega de um produto numa data e não receber nessa data". Prazos, preço, rastreabilidade e confiabilidade são avaliados como diferenciais competitivos entre as empresas e produtos. A falta de atrativos logísticos chega a resultar em desistências na intenção de compra, ou à busca por lojas físicas. Outro aspecto importante levantado dentro do contexto é o do comércio internacional, que foi associado negativamente à uma boa experiência pelo tempo de entrega.

Ainda em termos de complicações associadas à logística, outro aspecto de grande impacto negativo na experiência é o processo de devolução de um produto por conta de um defeito ou insatisfação. Em alguns casos, esse processo de troca demorou meses.

Um tema recorrente nas entrevistas foi o da compra de itens de vestuário online, pois entrevistados demonstraram muito receio em comprar itens de vestuário através de uma loja online, pois caso o caimento ou sensação do produto não agrade, percebem o processo de devolução como custoso e com alto nível de esforço, que não estariam dispostos a realizar, pois muitas vezes optam pelo e-commerce pela comodidade.

\subsubsection{O “jogo" da compra online}

Durante as entrevistas, foi levantado um tema pelos usuários sobre o processo de compra online que envolvia os riscos de comprar além do necessário pela facilidade e intangibilidade do dinheiro nesse ambiente. Por exemplo, um dos entrevistados mencionou:

"Eu não compro online porque é uma boa forma de perder dinheiro fácil, é igual ir ao mercado com fome. Você não vê o dinheiro, pode comprar várias coisas que não precisa" [...] "O aplicativo da Wish (https://www.wish.com/) parece um joguinho, e na realidade é você perdendo dinheiro" (Entrevistado 4) 
De fato, os pontos levantados pelos entrevistados se aproximam de certa forma de estudos científicos que avaliam o comportamento de compra quando realizado com dinheiro ou cartão de crédito e chegam à conclusão que no ambiente de pagamento com cartão os consumidores tendem a consumir mais (KHAN; CRAIG-LEES, 2009; KHAN; BELK; CRAIG-LEES, 2015).

\subsubsection{Redes de influência}

Não é recente o estudo do papel que a recomendação desempenha no processo de compra. A famosa recomendação boca-a-boca (DUHAN et al., 1997) possui seu correspondente online (CHEUNG et al., 2009), e esse tema também esteve presente nas entrevistas realizadas. Alguns usuários pontuaram que compraram em determinado lugar por recomendação de parentes, colegas de trabalho ou amigos. Uma outra parte dos entrevistados destacou que buscam análises dos produtos; um dos entrevistados destacou que a compra mais recente foi motivada por um influenciador digital.

Outro ponto de destaque dentro do tema da rede de influência, publicidade e publicização é o interesse que os entrevistados manifestaram pelo impacto socioambiental positivo. Em alguns casos essa temática foi central para a decisão de compra.

\subsubsection{As relações na compra}

Um dos pontos que diferencia a experiência online da experiência física é a ausência da interação física entre consumidores e representantes das marcas, por exemplo, funcionários, donos de estabelecimentos etc. No entanto, essa ausência de contato pode ser mitigada por ações de comunicação, por exemplo pequenas empresas que enviam cartões escritos à mão agradecendo a preferência da escolha do cliente. Para os grandes negócios, entrevistados comentaram sobre o envio de brindes e cupons de descontos para compras futuras, visando o relacionamento entre marca e consumidor.

\subsubsection{A vitrine online}

Na compra online, o conceito de "vitrine" também existe e muitos entrevistados parecem estar atentos quanto a isso. Um primeiro aspecto apontado é a facilidade em acessar o e-commerce, ou seja, acessibilidade e usabilidade de forma a conduzir o usuário pelos produtos, ofertas e benefícios das lojas online. Um dos pontos principais está relacionado à qualidade das imagens apresentadas no e-commerce. Pode parecer simples, mas vários entrevistados destacaram a importância de imagens do produto em alta qualidade. Para um dos entrevistados, a baixa qualidade das fotos ou da montagem do site desperta receio sobre a confiabilidade do produto e da segurança que o site possui, o que tende a desmotivar a compra.

\subsubsection{O desafio do vestuário}

Em quase todas as entrevistas, os entrevistados indicaram a preferência pela a compra de artigos de vestuário em lojas físicas. Identificou-se, por meio da análise das entrevistas, que existe um consenso: provar a vestimenta é uma etapa importante para tomar a decisão de compra nessa categoria. Quando o consumidor enxerga a necessidade de provar o produto para a tomar a decisão, foi observada a ocorrência de três padrões principais: o primeiro deles, o consumidor desiste da compra online e opta pela loja física; o segundo é quando o consumidor vai à loja experimentar o produto, e realiza a compra online motivado por um desconto exclusivo a este canal; o terceiro padrão é quando o consumidor teve um contato com o produto ou marca em uma experiência física passada e por isso se sente seguro para comprar online. 


\subsubsection{Síntese}

Os temas das entrevistas dialogam com a literatura (MERLE; SENECAL; ST-ONGE, 2012) ao apresentarem aspectos hedônicos - por exemplo, o "jogo da compra", "a vitrine online", "as relações na compra", entre outros - e utilitários - por exemplo, "Logística", "conforto e economia, entre outros. Os achados nas entrevistas serviram de insumo para a etapa de ideação. Destacam-se dois temas mais recorrentes nas entrevistas: Logística e o desafio do vestuário. De fato, a preocupação em receber o produto dentro do prazo é frequente entre os entrevistados e os atrasos são vistos como um elemento importante na construção de uma experiência ruim de compra online. Por sua vez, também foi frequentemente mencionada a dificuldade em se tomar uma decisão de compra em um ambiente online onde não existe a prova física da roupa. Nesse caso, verificou-se que esse era o principal contexto em que os entrevistados optaram em trocar o canal online pelo físico para efetivar a compra, pois não se sentiram suficiente seguros para realizá-la de forma online sem que antes tivessem provado o produto. Analisando os dois principais temas identificados a partir das entrevistas, verificou-se uma diferença importante, enquanto para o desempenho logístico os critérios para a criação de uma boa experiencia se mostraram mais objetivos, para o caso da dificuldade de prova de roupa, essa percepção é mais complexa. Por exemplo, quando se referiam à logística, tanto nas entrevistas quanto nos dados do website "Reclame Aqui", uma boa experiência era frequentemente relacionada, por exemplo, ao cumprimento do prazo informado no ato da compra, a garantia da chegada do produto sem avarias e a visibilidade do processo logístico, desde a efetivação do pedido até a conclusão da entrega. Esses critérios são, de certa forma, quantificáveis e muito associados com a qualidade do serviço logístico. Apesar dos imensos desafios que o contexto brasileiro inerentemente impõe ao serviço logístico, a contratação de um bom prestador de serviço ou o investimento em frota e tecnologia parece atender ao critério minimamente desejado de cumprimento dos prazos previstos. De forma diferente ocorre com a experiência da prova de roupa. Primeiro, existe uma falta de padronização das modelagens no Brasil, o que faz com que um tamanho possa assumir um intervalo de medidas relativamente alto, resultando em dificuldade da compra de itens de vestuário (VICTOR; ROCHA, 2011). Além disso, a diversidade de biótipos também contribui para que não somente o tamanho, mas o caimento seja uma variável importante no processo de decisão de compra de uma peça de roupa. Por fim, eliminar a experiência física de prova desse processo parece impor a necessidade da existência de outros elementos no ambiente online, que parecem não terem sidos totalmente explorados, para suprir essa ausência de prova física. Dessa maneira, dada a subjetividade do tema e complexidade associada à percepção dos indivíduos, o tema do desafio do vestuário se mostra interessante para ser abordado pela disciplina do design.

\subsection{Processos de inspiração em canvas}

Os resultados foram analisados em grupo através de artefatos de design thinking, a maioria no modelo de canvas. Primeiro, criou-se uma persona que representasse o principal perfil verificado nas entrevistas, uma "personagem" que possui idade entre 20 e 30 anos, mora em uma grande cidade como São Paulo e compra, em média, duas vezes no mês (Figura 3). 

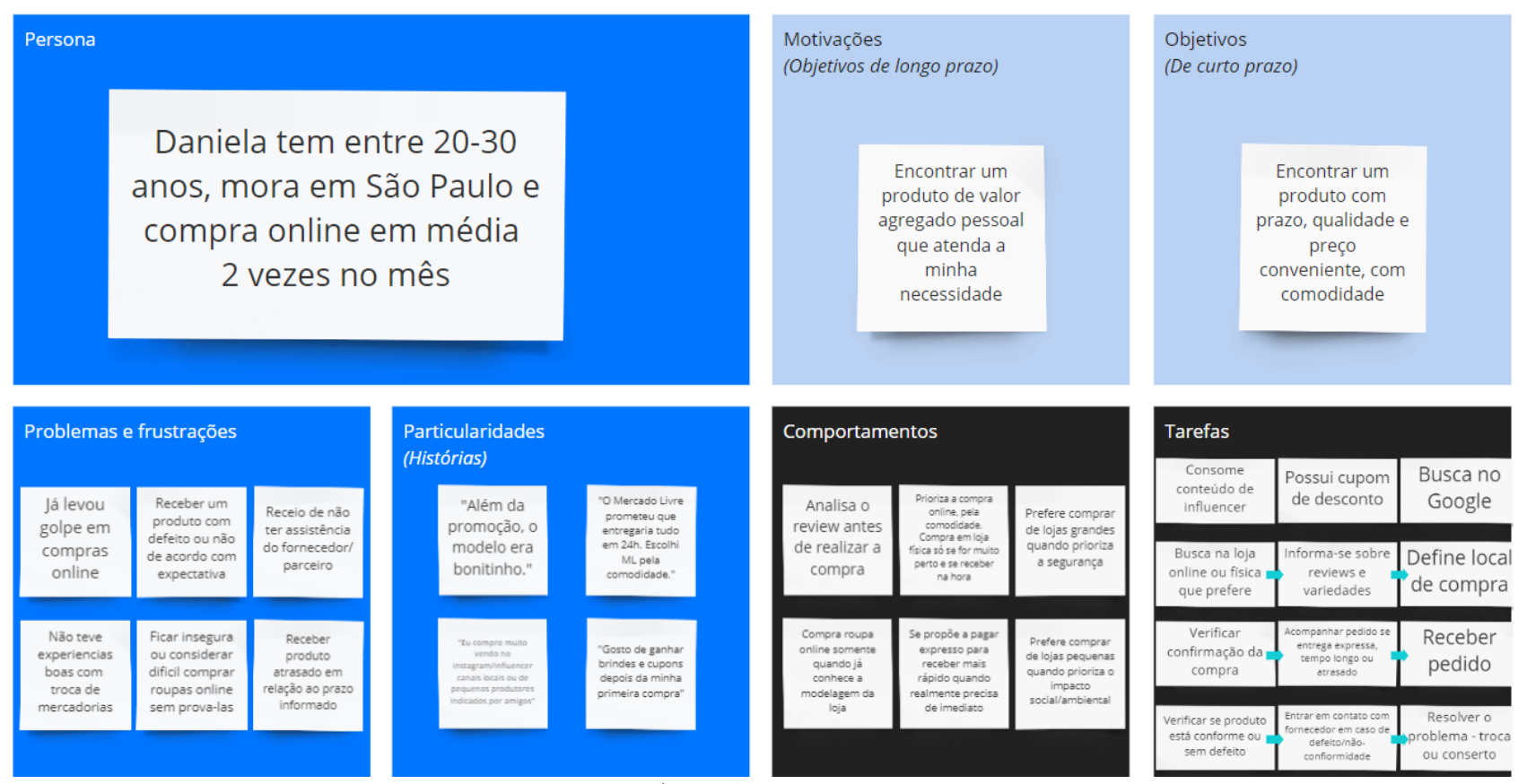

Figura 3 - Persona.

Fonte: Elaborado pelos autores.

A persona foi apelidada Daniela, e busca atender sua necessidade pela compra de produtos que sejam de boa qualidade, com preço equiparado ao praticado ou menores do que no canal físico, que possua uma entrega confiável, podendo desfrutar da comodidade de não ter que se deslocar para realizar uma compra. Suas frustrações incluem o receio de estar exposta em termos de segurança da informação na internet e receber um golpe enquanto realiza alguma compra online; ou não conseguir trocar um produto em caso de defeito ou arrependimento. Daniela se sente ainda mais insegura ao comprar roupas online, pois não consegue proválas. A persona ajuda a tipificar hábitos encontrados nas entrevistas, como analisar comentários de outros consumidores sobre os produtos antes de realizar uma compra online, acreditar que lojas maiores trazem mais segurança, mas buscar impacto social positivo ao comprar de pequenos negócios. A criação de um personagem como a Daniela traz agilidade e pragmatismo ao processo de design, e foi de grande valor aos pesquisadores - a abstração feita através da leitura das 12 entrevistas cria uma referência mental sobretudo durante as fases de ideação, omitindo traços específicos de um ou outro entrevistado (uma das pessoas, por exemplo, era quase avessa às compras online por preocupações de segurança, enquanto que a Daniela melhor representa a maioria dos participantes porque demonstra preocupação moderada) e focando em comportamentos gerais, de conhecimento compartilhado entre o grupo de pesquisadores. Esses pontos complementares foram levantados com a confecção do mapa de empatia, sintetizando ainda mais as dores e desejos de um cliente ou usuário (Figura 4). O conteúdo do mapa de empatia busca "síntese das informações sobre o cliente numa visualização do que ele diz, faz, pensa e sente. Assim, possibilita a organização dos dados da fase de Imersão de forma a prover entendimento de situações de contexto, comportamentos, preocupações e até aspirações do usuário (ou outros atores estudados)" (VIANNA, et al., 2012, p.83). 


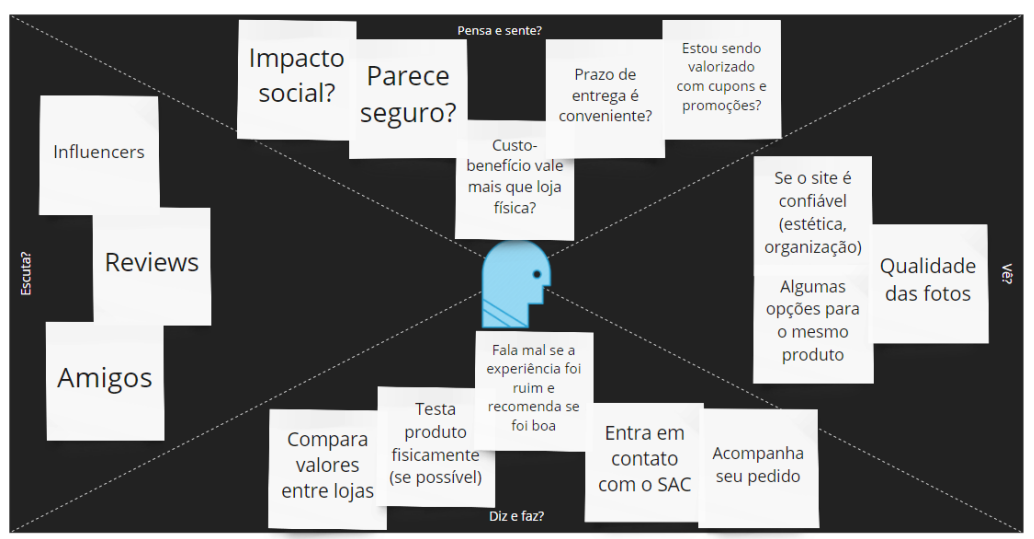

Figura 4 - Mapa de empatia.

Fonte: Elaborado pelos autores.

Para complementar este processo em que são criadas hipóteses de o que uma pessoa pensa ou sente, criou-se a "jornada do usuário": identificando os momentos, tarefas realizadas e seus objetivos, os pontos de contato entre usuário e produto (touchpoints), relacionando com os sentimentos e dores. A Figura 5 apresenta essa jornada.

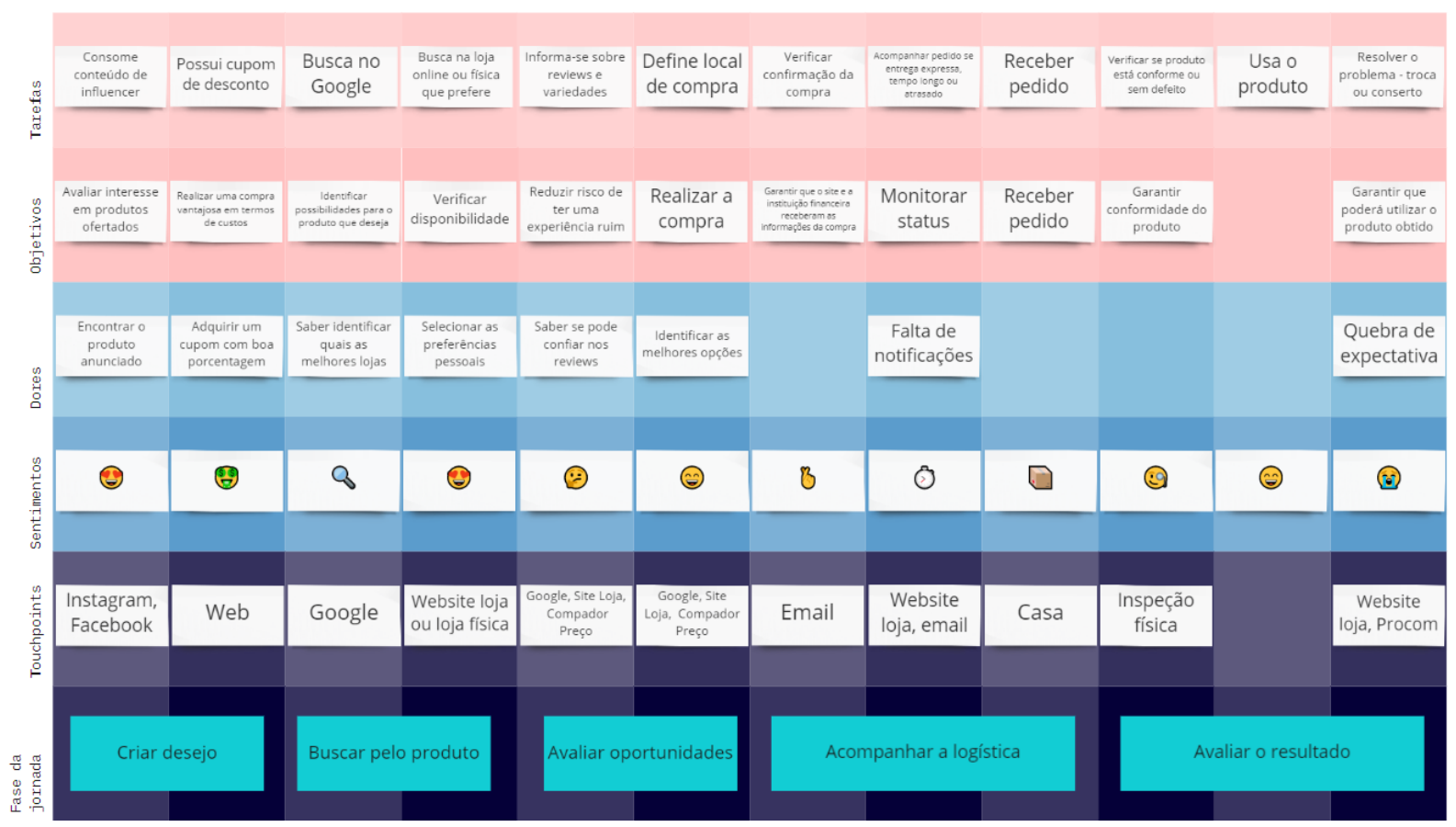

Figura 5 - Jornada do usuário.

Fonte: Elaborado pelos autores.

Essas dinâmicas e mecanismos buscam a síntese do repertório obtido durante a fase de inspiração, e o resultado do processo foi a criação do chamado "ponto de vista" (Figura 6), com uma pequena história que explicita a maior dor da persona em seu próprio ponto de vista, sendo que a etapa seguinte, a "ideação", busca criar ideias que solucionam essa dor. 


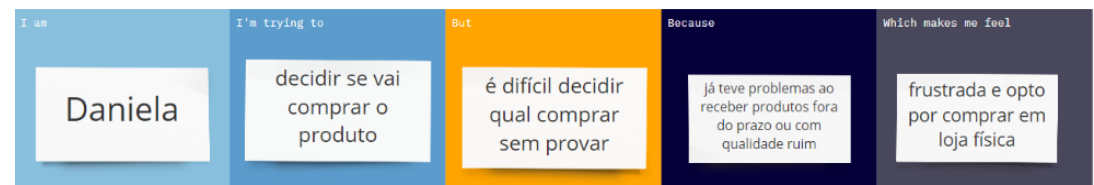

Figura 6 - Ponto de vista.

Fonte: Elaborado pelos autores.

Com base nos conteúdos levantados, entendeu-se que uma das principais dores da experiência e-commerce é a dificuldade de comprar produtos online sem conseguir prová-las da maneira tradicional que existe nas lojas. A escolha foi motivada principalmente pela transversalidade do tema ao longo das entrevistas realizadas, pois esse tema esteve presente em quase todas as narrativas e muitas vezes associadas às experiências em que o usuário optou pela troca do meio online para o físico para poder realizar a compra. Inegavelmente, existe uma diversidade grande de dores nesse meio, basta citar exemplos da Figura 3 , como aspectos de segurança de dados e qualidade de serviço, que esse estudo, em seu momento exploratório, trouxe para a literatura e que podem ser explorados em estudos futuros.

\subsection{Desenvolvimento do protótipo}

A principal hipótese se resume à ideia de que as pessoas fariam compras de roupa online com mais conforto caso pudessem saber como o produto ficaria em seu corpo, sendo essa a proposta de valor que guiou o desenvolvimento do PMV. Por meio das ferramentas de prototipagem Marvel, Figma e Axure RP 9 foi construída uma interface que espelha plataformas de comércio eletrônico conhecidas por muitos dos que vivem em grandes centros urbanos (no caso, Mercado Livre e Amazon, que foram bastante referenciadas durante as entrevistas) com a adição de um elemento de botão onde lia-se o texto "ver o caimento da roupa", que aciona a ferramenta idealizada pelo grupo de pesquisa. Utilizou-se interfaces de plataformas conhecidas para evitar dificuldades relacionadas à usabilidade, leitura, ou confiança nessa etapa do protótipo - navegar pela interface da loja não possui relação com a hipótese a ser testada.

Por meio do acionamento do botão, o usuário do protótipo encontra uma interface onde o texto explica que será apresentado um modelo de acordo com as informações de peso e altura que podem ser digitadas (Figura 7, a). O conceito por trás de usar essas duas medidas surgiu a partir da preocupação em identificar o Índice de Massa Corpórea (IMC) e assim apresentar um resultado minimamente parecido visualmente com o usuário, dando a sensação de "experimentar" a peça de roupa (camisa branca) que foi exibida no comércio eletrônico. Poderíamos apresentar resultados mais precisos com informações adicionais, como medidas do busto, ombros, cintura e biótipo, porém muitas pessoas não saberiam dizer esses dados sobre si mesmas, além disso a inclusão dessas variáveis complicaria o desenvolvimento do protótipo, sendo que sua exclusão não necessariamente invalidaria a validação da hipótese.
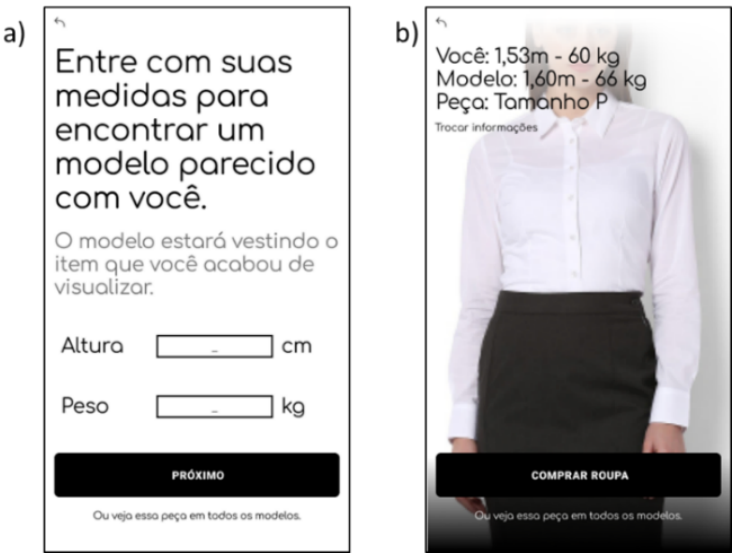

Figura 7 - Representação do protótipo desenvolvido, figura (a) esquerda, figura (b) direita. Fonte: Elaborado pelos autores a partir de imagens abertas da internet. 
Com os dados do usuário, o sistema desenvolvido para o protótipo recomenda um modelo de IMC similar ao usuário e vestido do mesmo item (camisa branca) que foi anunciado na loja virtual, assim facilitando uma comparação visual entre modelo, peça e usuário, e isso traria mais conforto para a tomada de decisão sobre comprar ou não a roupa. Para ajudar nessa comparação visual, o protótipo indica ao usuário as medidas reais do modelo, a medida da peça (dentre as diversas possibilidades entre as menores e as maiores) e reafirma as medidas que o usuário tem, para mostrar que o resultado é personalizado e tentar aproximá-lo do exibido no modelo. Por simplicidade que essa etapa requer, as imagens dos modelos foram retiradas da internet, por essa razão as medidas incluídas no PMV foram estabelecidas por meio de aproximações. Um dos resultados pode ser observado na Figura 7 (b). Por último, o protótipo possui uma função de galeria onde são exibidos todos os modelos disponíveis vestindo a peça anunciada na loja. Essa função é independente das medidas do usuário, e pode ser acessada sem que nenhuma informação seja disponibilizada. O conceito por trás dessa parte da ferramenta vêm na linha de permitir que o usuário encontre outro modelo com quem eventualmente se identifique mais, em caso de não estar satisfeito com a recomendação do protótipo, ou querer visualizar como a peça ficaria no caso de um presente; além disso, a visualização da galeria ajuda a comunicar a proposta da ferramenta, foi um dos facilitadores identificados tanto na literatura quanto nas entrevistas realizadas, e permite que esta seja usada até mesmo por quem não deseja colocar informação alguma sobre si próprio. As hipóteses foram testadas em um grupo de dez usuários e 12 lojistas para entender a aceitação tanto do lado da oferta quanto da demanda e os resultados são apresentados na próxima seção.

\subsection{Teste}

Após a construção do protótipo foram feitos dois testes. Um com dez pessoas dentro do perfil de possíveis consumidores de comércio eletrônico em grandes centros urbanos e outro com 12 lojistas que poderiam ser os consumidores do potencial serviço/produto.

\subsubsection{Usuário}

As entrevistas foram feitas online através de ferramentas de videoconferência e compartilhamento de tela e vídeo, para que os pesquisadores pudessem acompanhar as diferentes reações ao protótipo ao longo da conversa. Os participantes do teste do protótipo tinham entre 20 e 36 anos, hábitos de compra variados e diversidade de IMC e gênero. Parte do roteiro do teste consistia em instruir o participante de que, hipoteticamente, este deve comprar uma camisa branca para que o pesquisador possa observar o que o usuário faria dentro de um contexto simulado, e com o uso da ferramenta no protótipo, sendo algumas possibilidades consideradas: comprar o produto; não comprar o produto; procurar outro modelo; procurar outra peça; procurar outro tamanho; desistir da compra no ambiente virtual.

As entrevistas resultaram em impressões positivas e negativas. Todos entenderam do que se tratava a ferramenta e do valor que ela pretendia entregar; o fator mais controverso foi a precisão do resultado no momento de apresentar a imagem de um modelo. Sete dos participantes indicaram que sua decisão foi influenciada pelo resultado da ferramenta, ou seja, disseram se sentir mais confiante em sua decisão por ter visto os modelos vestindo a peça que estava sendo vendida, e justamente não compraram, pois não gostaram da peça e/ou não possuía o tamanho que desejava.

Por conta desses casos o protótipo seria sujeito a uma etapa de iteração, ou pivot. As iterações são feitas para buscar resolver essas controvérsias e evidenciar o que foi percebido como positivo.

Destaca-se que um sistema de recomendação de tamanho é uma solução que contorna em partes a ausência da prova de roupa física durante a experiência online; junto com o fornecimento de medidas da peça e dos modelos, essas informações adicionais trazem alívios para as dores dos usuários identificadas. Ademais, a complementaridade da recomendação com as imagens dos modelos contribui para ilustrar e fazer com as 
pessoas possam visualizar a peça em seus corpos. Sendo assim, trazer vários tipos de biótipos nas fotos é uma solução que contribuiria para dar mais segurança para que os consumidores façam as suas compras. Outro aspecto ainda dentro do tema visual, seria o uso de mais imagens.

\subsubsection{Lojistas}

Como forma de explorar o potencial financeiro da solução, alguns potenciais clientes foram consultados, no caso, lojistas que poderiam ter interesse na ferramenta para auxiliar em suas vendas. As entrevistas com os 12 lojistas foram feitas de forma virtual por meio de um aplicativo de troca de mensagens instantâneas e de forma não estruturada. A partir da análise do retorno das respostas, foram identificadas impressões positivas e negativas: metade venderia o produto com maior assertividade; cinco disseram que venderiam o produto, mas continuam incerto se o cliente visualizaria o caimento; enquanto um não venderia o produto, pois ainda acha que o cliente gostaria de experimentar na loja. Entre os comentários positivos, obteve-se: "A cliente gosta de ver fotos no manequim ou no corpo e querem saber medidas. Gostei da ferramenta e as confecções teriam que deixar de fazer o mesmo molde e se adaptar como alfaiataria" (Lojista 5).

Por sua vez, entre os comentários negativos, verificou-se: "Fazer em 3D para que o cliente visualize melhor" (Lojista 7).

Assim como na pesquisa do usuário, todos entenderam do que se trata a ferramenta e do valor que ela pretendia entregar e por conta dos resultados obtidos, o protótipo seria sujeito a uma etapa de iteração, ou pivot, para a inclusão de atributos adicionais, como fotos que permitissem ao usuário uma visualização em diferentes perspectivas para suprir a necessidade da visualização "3D" apontada pelo participante 7 e a inclusão de medidas adicionais e secundárias para que o consumidor final que tipo de informação deseje inserir caso a informação do peso não seja algo confortável, como sugere o participante 8. A partir destes testes, um esboço do serviço a ser ofertado e seu enquadramento nas necessidades e dores do cliente do $e$ commerce pode ser verificado no canvas da proposta de valor na Figura 8:

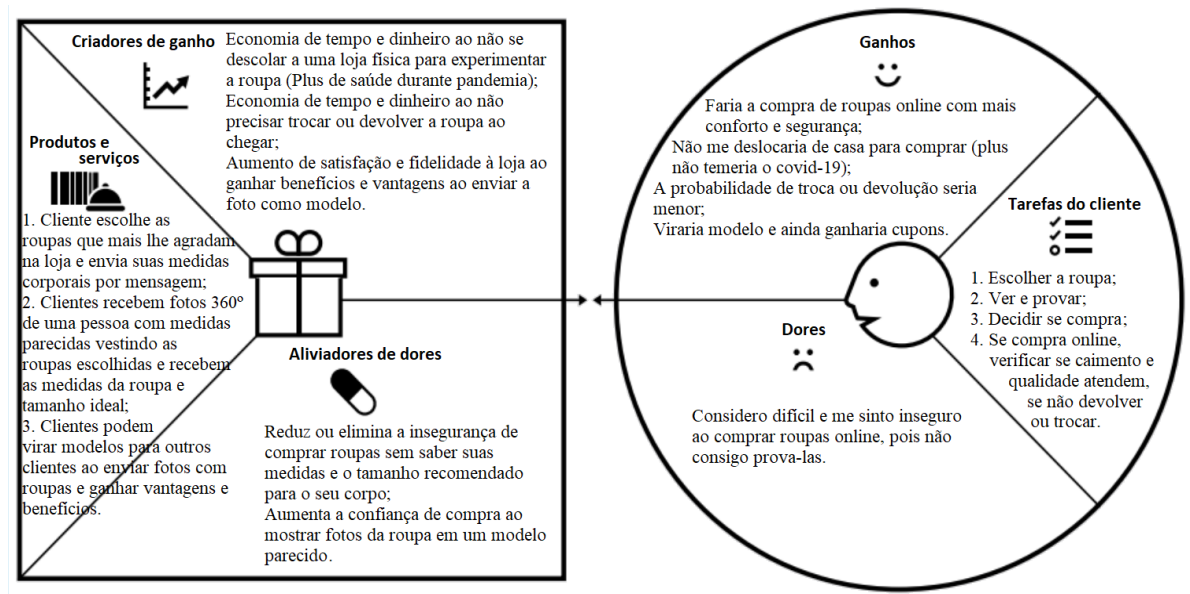

Figura 8 - Canvas da proposta de valor.

Fonte: Elaborado pelos autores.

\section{Conclusões}

O presente estudo apresentou uma solução capaz de contribuir para a melhoria da experiência de compra online de peças de vestuário por usuários de e-commerce. Foi observado que, a recomendação de tamanho para os consumidores é uma fonte importante na construção da confiança para realizar a compra online. Ademais, a existência de fotos de modelos com biótipos diversos usando a mesma peça de vestuário facilita 
que o consumidor se enxergue representado e se sinta mais confortável para a compra online. Além disso, fotos de diversos ângulos e de boa qualidade, junto com informações das peças e dos modelos, são importantes para complementar a segurança na decisão. Os resultados complementam e expandem uma visão existente na literatura que busca desenvolver representações virtuais em três dimensões dos seres-humanos: os usuários se sentem mais confortáveis quando conseguem se sentir representados na imagem que veem. Esse resultado pode ser obtido pelos avanços tecnológicos e melhorias na representação virtual como estudos da literatura tem trazido, mas também pode ser obtido quando, nas fotos, existem modelos com diferentes tipos de biótipos e suas respectivas informações. Dessa forma, a solução proposta neste estudo, teria o potencial de obter benefícios similares àqueles que o desenvolvimento tecnológico tem buscado e com potencial custo menor. O que reforça a recomendação de Merle, Senecal e ST-Onge (2012) de cuidado no investimento das ferramentas tecnológicas de interatividade de imagem e o retorno que se espera delas. Dessa maneira, o estudo contribui para a prática e para a teoria. Primeiro, explora e desenvolve uma proposta de solução que pode ser tanto implantada totalmente quanto parcialmente pelas empresas que comercializam roupas para melhorar a experiência de compra dos usuários

Além disso, explora o uso do design thinking para a solução de problemas dentro do contexto do $e$ commerce, trazendo não somente uma solução proposta, mas também a descrição de todo o processo muitas vezes não linear e de complexa narrativa por conta da lógica abdutiva - de construção dessa solução. A escolha do design thinking como forma de condução de um processo investigativo também se mostrou interessante para a identificação de problemas, pois apesar do afunilamento previsto para o problema e para solução, toda a identificação de problemas que ocorre durante o processo pode ser potencialmente benéfica para explorações futuras. Torna-se interessante mencionar também, que ao partir de um tema aberto, um ponto de atenção deve estar no tempo de condução de um processo de design thinking, que deve considerar a construção de repertório necessária para a convergência em um problema relevante para o contexto estudado e o tempo de construção de uma proposta de solução que tenha o usuário como centro, e que por isso demanda uma dedicação para observá-lo e investigá-lo. Em termos metodológicos, ainda que possam ser utilizados alguns métodos quantitativos em determinada etapa do processo de investigação, o design thinking, por conta da sua orientação ao usuário, parece estar ligado principalmente às técnicas de levantamento de dados majoritariamente utilizadas em métodos qualitativos, pois tendem a ser efetivas para a captura da percepção dos indivíduos em relação ao fenômeno estudado. Essa flexibilidade do design thinking quanto ao uso de diversas técnicas de coleta de evidências se mostra interessante, pois permite identificar temas convergentes. Por exemplo, nesse estudo, a análise dos dados secundários do website "Reclame Aqui" indicou a logística como um problema relevante para o e-commerce e que dialoga com os resultados das entrevistas que indicaram que essa é também uma dor dos entrevistados. Similarmente, a presença de alta proximidade entre o envolvimento do usuário com aspectos visuais identificado na análise de conteúdo dos textos levantados na revisão sistemática da literatura é reforçada com uma parte dos achados desse estudo que destaca a importância da visualização de imagens na decisão de compra online de itens de vestuário.

No entanto, o estudo possui limitações. Primeiro, ao partir de um problema aberto para um específico, deliberadamente houve a escolha pela dor entendida como sendo a principal da persona criada - que era a experiência de prova de peças de vestuário - não abordando outros problemas identificados e existentes. Além disso, a escolha dos métodos impõe uma limitação à generalização ao objeto, que foi uma compensação sabida para que se pudessem ser investigadas em profundidade as percepções dos usuários do e-commerce. Além disso, foi realizada para a realidade de metrópoles do Brasil para um grupo de usuários de uma faixa específica de idade, mas complementa estudos realizados em outros países. Por fim, a solução dialoga com ferramentas similares no mercado, mas é mais completa ao fornecer um panorama da dor investigada.

Em suma, o estudo mostrou que o design thinking é capaz de explorar um determinado problema através de múltiplas perspectivas e fontes de dados, gerando um repertório rico para a construção de uma solução que 
lide com as complexidades da natureza humana. Além disso, abre espaço para um rol elevado de melhorias nos processos existentes. Por isso, como agenda futura, além de avançar no detalhamento da implementação da solução proposta neste estudo, sugere-se que os demais temas identificados nas entrevistas sejam investigados em profundidade a fim de contribuir também para a construção de uma boa experiência de compra online.

\section{Referências Bibliográficas}

ALSHENQEETI, H. Interviewing as a data collection method: A critical review. English Linguistics Research, v. 3, n. 1, p. 39-45, 2014.

BECKMAN, S. L.; BARRY, M. Innovation as a learning process: Embedding design thinking. California Management Review, v. 50, n. 1, p. 25-56, 2007.

BERRY, L. L.; CRANE, J. ; DEMING, K. A.; BARACH, P. Using Evidence to Design Cancer Care Facilities. American Journal of Medical Quality, p. 1062860619897406, 2020.

BHATTACHARYYA. S. How retailers are recouping costs from returned merchandise. DIGIDAY. Disponível em $<$ https://digiday.com/retail/retailers-recouping-costs-returned-

merchandise/\#: : :text=According\%20to\%20consulting\%20firm\%20CBRE,depending\%20on $\% 20$ the $\% 20$ pro duct $\% 20$ type $>$ Acesso em junho 2020.

BLANK, S. Why the lean start-up changes everything? Harvard Business Review, 2017.

BRENNER, W.; UEBERNICKEL, F.; ABRELL, T. Design thinking as mindset, process, and toolbox. In: Design Thinking for Innovation. Springer, Cham, 2016. p. 3-21.

BROWN, T. Design thinking. Elsevier, 2010

BROWN, T.; WYATT, J. Design thinking for social innovation. Development Outreach, v. 12, n. 1, p. 2943, 2010.

CAI, L.; HE, X.; DAI, Y.; ZHU, K. Research on B2B2C E-commerce website design based on user experience. In: Journal of Physics: Conference Series. 2018. p. 1-5.

CAMERE, S.; BORDEGONI, M. A strategy to support Experience Design process: the principle of Accordance. Theoretical Issues in Ergonomics Science, v. 16, n. 4, p. 347-365, 2015.

CAMERON, D. Electronic Commerce: The New Business Platform of the Internet. Charleston: Computer Technology Research Corp, 1997.

CHARLON, G. Ecommerce Returns: 2020 Stats and Trends. SaleCycle. Disponível em< https://www.salecycle.com/blog/featured/ecommerce-returns-2018-stats-trends/> Acesso em 09/08/2020.

CHE, Y. K. Customer return policies for experience goods. The Journal of Industrial Economics, p. 17-24, 1996.

CHEN, L. D.; TAN, J. Technology adaptation in e-commerce: key determinants of virtual stores acceptance. European Management Journal, v. 22, n. 1, p. 74-86, 2004. 
CHEUNG, M. Y.; LUO, C.; SIA, C.; CHEN, H.; Credibility of electronic word-of-mouth: Informational and normative determinants of on-line consumer recommendations. International Journal of Electronic commerce, v. 13, n. 4, p. 9-38, 2009.

CLACK, L.; STÜHLINGER, M.; MEIER, M. T.; WOLFENSBERGER, A. et al. User-centred participatory design of visual cues for isolation precautions. Antimicrobial Resistance \& Infection Control, v. 8, n. 1, p. 179, 2019.

CLEMES, M. D.; GAN, C.; ZHANG, J. An empirical analysis of online shopping adoption in Beijing, China. Journal of Retailing and Consumer Services, v. 21, n. 3, p. 364-375, 2014.

CONTRERAS, D.; SALAMÓ, M.; RODRÍGUEZ, I.; PUIG, A. et al. Supporting Users Experience in a 3D eCommerce Environment. In: Proceedings of the XVI International Conference on Human Computer Interaction. 2015. p. 1-4.

DAYIK, Mehmet; COLAK, Oguz; YÜKSEL, Hakan. Real-time virtual clothes try-on system/Sistem virtual de probare a îmbracamintei în timp real. Industria Textila, v. 67, n. 6, p. 396, 2016.

DING, Y. S.; XU, Y. C. Intelligent optimal selection of garment sizes by using immune algorithm and AHP method. Journal of the Textile Institute, v. 99, n. 3, p. 281-286, 2008.

DUC, A. N.; ABRAHAMSSON, P. Minimum viable product or multiple facet product? The Role of MVP in software startups. In: International Conference on Agile Software Development. Springer, Cham, 2016. p. 118-130.

DUHAN, D. F.; JOHNSON, S. D.; WILCOX, J. ; HARRELL, G. D. Influences on consumer use of word-ofmouth recommendation sources. Journal of the Academy of Marketing Science, v. 25, n. 4, p. 283, 1997.

EINES, T. F.; VATNE, S. Nurses and nurse assistants' experiences with using a design thinking approach to innovation in a nursing home. Journal of Nursing Management, v. 26, n. 4, p. 425-431, 2018.

FLEURY, A. L.; STABILE, H.; CARVALHO, M. M. An overview of the literature on design thinking: trends and contributions. The International Journal of Engineering Education, v. 32, n. 4, p. 1704-1718, 2016.

FURNHAM, A. The brainstorming myth. Business Strategy Review, v. 11, n. 4, p. 21-28, 2000.

GLEN, R.; SUCIU, C.; BAUGHN, C.; ANSON, R. Teaching design thinking in business schools. The International Journal of Management Education, v. 13, n. 2, p. 182-192, 2015.

GONÇALVES, R.; ROCHA, T.; MARTINS, J. L. B. R.; BRANCO, F. et al. Evaluation of e-commerce websites accessibility and usability: an e-commerce platform analysis with the inclusion of blind users.

Universal Access in the Information Society, v. 17, n. 3, p. 567-583, 2018.

GRAN VIEW RESEARCH. B2C E-commerce Market Size, Share \& Trends Analysis Report by Type (B2C Retailers, Classifieds), By Application (Home Décor \& Electronics, Clothing \& Footwear), By Region, And Segment Forecasts, 2020 - 2027. Disponível em https://www.grandviewresearch.com/industry-analysis/b2ce-commerce-market Acesso junho 2020. 
GUO, Z.; ZHANG, D.; FENG, S.; LIN, S. et al. Structural design and optimization of a panel-based fitting robot. Journal of Advanced Mechanical Design, Systems, and Manufacturing, v. 12, n. 4, p.

JAMDSM0091-JAMDSM0091, 2018.

HARUN, A.; ISMAIL, J.; SHIANG, H. Y.; NOOR, N. L. M. et al. An exploratory study in conceptualizing user view on digital taste using design thinking. Indonesian Journal of Electrical Engineering and Computer Science, v. 17, n. 1, p. 379-388, 2019.

HAUSWIESNER, S.; STRAKA, M.; REITMAYR, G. Virtual try-on through image-based rendering. IEEE Transactions on Visualization and Computer Graphics, v. 19, n. 9, p. 1552-1565, 2013.

HOWARD, T. Journey mapping: A brief overview. Communication Design Quarterly Review, v. 2, n. 3, p. $10-13,2014$

HUDÁK, M.; KIANIČKOVÁ, E.; MADLEŇÁK, R. The importance of e-mail marketing in e-commerce. Procedia Engineering, v. 192, p. 342-347, 2017.

IYER, K. N. S.; GERMAIN, R.; FRANKWICK, G. L. Supply chain B2B e-commerce and time-based delivery performance. International Journal of Physical Distribution \& Logistics Management, 2004.

JIANG, S.; WU, Y.; FU, Y. Deep bidirectional cross-triplet embedding for online clothing shopping. ACM Transactions on Multimedia Computing, Communications, and Applications (TOMM), v. 14, n. 1, p. 1-22, 2018.

KAJORNBOON, A. B. Using interviews as research instruments. E-Journal for Research Teachers, v. 2, n. 1, p. 1-9, 2005.

KALAKOTA, R.; WHINSTON, A. Electronic Commerce: A Manager's Guide. New York: AddisonWesley, 1997.

KALAKOTA, R.; ROBINSON, M. E-Business: Estratégias para alcançar sucesso no mundo digital. $2^{\text {a }}$ ed. São Paulo: Bookman, 2002.

KHAN, J.; BELK, R. W.; CRAIG-LEES, M. Measuring consumer perceptions of payment mode. Journal of Economic Psychology, v. 47, p. 34-49, 2015.

KHAN, J.; CRAIG-LEES, M. 'Cashless' transactions: perceptions of money in mobile payments. International Business and Economics Review, v. 1, n. 1, 2009.

KOUFARIS, M.; KAMBIL, A.; LABARBERA, P. A. Consumer behavior in web-based commerce: an empirical study. International Journal of Electronic Commerce, v. 6, n. 2, p. 115-138, 2001.

LEMON, Katherine N.; VERHOEF, Peter C. Understanding customer experience throughout the customer journey. Journal of Marketing, v. 80, n. 6, p. 69-96, 2016.

LIM, S. F.; JIN, X.; SRAI, J. S. Consumer-driven e-commerce. International Journal of Physical Distribution \& Logistics Management, 2018.

LIN, C. J.; CHENG, L. Y. An integrated model of service experience design improvement. The Service Industries Journal, v. 35, n. 1-2, p. 62-80, 2015. 
MAJID, E. S. A.; KAMARUDDIN, N.; MANSOR, Z. Adaptation of usability principles in responsive web design technique for e-commerce development. In: 2015 International Conference on Electrical Engineering and Informatics (ICEEI). IEEE, 2015. p. 726-729.

MERLE, A.; SENECAL, S.; ST-ONGE, A. Whether and how virtual try-on influences consumer responses to an apparel web site. International Journal of Electronic Commerce, v. 16, n. 3, p. 41-64, 2012.

MITTAL, A. E-commerce: It's Impact on consumer Behavior. Global Journal of Management and Business Studies, v. 3, n. 2, p. 131-138, 2013.

MOROZ, Miroslaw. Tendency to Use the Virtual Fitting Room in Generation Y-Results of Qualitative Study. Foundations of Management, v. 11, n. 1, p. 239-254, 2019.

NEWHOOK, R.; JARAMILLO, D.; TEMPLE, J. G.; DUKE, K. J. Evolution of the mobile enterprise app: A design perspective. Procedia Manufacturing, v. 3, p. 2026-2033, 2015.

NGAI, Eric WT; WAT, F. K. T. A literature review and classification of electronic commerce research. Information \& Management, v. 39, n. 5, p. 415-429, 2002.

OLSEN, G. Persona creation and usage toolkit. Retrieved March, v. 25, p. 2014, 2004.

PAPADOPOUOU, P.; KANELLIS, P.; MARTAKOS, D. Investigating trust in e-commerce: a literature review and a model for its formation in customer relationships. AMCIS 2001 Proceedings, p. 155, 2001.

PAVLOU, P. A.; CHAI, L. What drives electronic commerce across cultures? Across-cultural empirical investigation of the theory of planned behavior. J. Electron. Commerce Res., v. 3, n. 4, p. 240-253, 2002.

RIES, Eric. Minimum viable product: a guide. Startup lessons learned, v. 3, 2009. Disponível em: http://soloway.pbworks.com/w/file/fetch/85897603/1\%2B\%20Lessons\%20Learned \%20Minimum\%20Viab le\%20Product \%20a\%20guide2.pdf acesso em outubro de 2020.

SAHI, G. User satisfaction and website usability: Exploring the linkages in B2C e-commerce context. In: 2015 5th International Conference on IT Convergence and Security (ICITCS). IEEE, 2015. p. 1-4.

SCHIFFER, J. The unsustainable cost of free returns. Vogue Business. Disponível em < https://www.voguebusiness.com/consumers/returns-rising-costs-retail-environmental> Acesso em: $09 / 08 / 2020$.

SHEN, Y. Emerging scenarios of data infrastructure and novel concepts of digital libraries in intelligent infrastructure for human-centred communities: A qualitative research. Journal of Information Science, v. 45, n. 5, p. 691-704, 2019.

SO, C. What Makes Good Design? Revealing the Predictive Power of Emotions and Design Dimensions in Non-Expert Design Vocabulary. The Design Journal, v. 22, n. 3, p. 325-349, 2019.

STEPHENS, J. P.; BOLAND, B. J. The aesthetic knowledge problem of problem-solving with design thinking. Journal of Management Inquiry, v. 24, n. 3, p. 219-232, 2015.

TRANFIELD, D.; DENYER, D.; SMART, P. Towards a methodology for developing evidence-informed management knowledge by means of systematic review. British Journal of Management, v. 14, n. 3, p. 207222, 2003. 
TSAGKIAS, M.; MURDOCK, V. Challenges and Research Opportunities in eCommerce Search and Recommendations. In: SIGIR Forum. 2020.

TSCHIMMEL, K. Design thinking as an effective Toolkit for Innovation. In: ISPIM Conference Proceedings. The International Society for Professional Innovation Management (ISPIM), 2012. p. 1.

UNGERER, C.; PORTUGAL, A.; MOLINUEVO, M.; ROVO, N. Recommendations to Leverage Ecommerce During the COVID-19 Crisis. 2020.

VÄÄNÄNEN-VAINIO-MATTILA, K.; OLSSON, T.; HÄKKILÄ, J. Towards deeper understanding of user experience with ubiquitous computing systems: systematic literature review and design framework. In: IFIP Conference on Human-Computer Interaction. Springer, Cham, 2015. p. 384-401.

VIANNA, M.; VIANNA, Y.; ADLER, I. K.; LUCENA, B.; RUSSO B. Design thinking. Inovação em negócios, 2012.

VICTOR, D.M.R.; ROCHA, R.E.V. Padronização e normalização de tamanhos de peças de vestuário percepções de fabricantes. Usiness, v. 9, n. 9, p. 51-65, 2011.

YIN, R. K. Estudo de Caso: Planejamento e métodos. Bookman editora, 2011.

YOO, W.; YU, E.; JUNG, J. Drone delivery: Factors affecting the public's attitude and intention to adopt. Telematics and Informatics, v. 35, n. 6, p. 1687-1700, 2018.

YU, Y.; WANG, X.; ZHONG, R. Y; HUANG, G. Q. E-commerce logistics in supply chain management: Practice perspective. Procedia Cirp, 2016.

YUAN, M.; KHAN, I. R.; FARBIZ, F.; YAO, S. S. A mixed reality virtual clothes try-on system. IEEE Transactions on Multimedia, v. 15, n. 8, p. 1958-1968, 2013.

\section{Agradecimentos}

Agradecemos aos professores André Leme Fleury e Rosana Vasques, da Universidade de São Paulo, que contribuíram direta e indiretamente na escrita deste artigo, apoiando, revisando e dando valiosas sugestões do início ao fim. 